Canadian

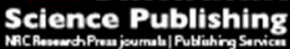

Canadian Geotechnical Journal Revue canadienne de géotechnique

\title{
THERMAL PROPERTIES OF ENGINEERED BARRIERS FOR A CANADIAN DEEP GEOLOGICAL REPOSITORY
}

\begin{tabular}{|r|l|}
\hline Journal: & Canadian Geotechnical Journal \\
\hline Manuscript ID & cgj-2017-0150.R1 \\
\hline Manuscript Type: & Article \\
\hline Date Submitted by the Author: & $13-$ Sep-2017 \\
\hline $\begin{array}{r}\text { Complete List of Authors: } \\
\text { Is the invited manuscript for } \\
\text { consideration in a Special } \\
\text { Issue? : }\end{array}$ & N/A \\
\hline Keyword: & $\begin{array}{l}\text { deep geologic repository, bentonite, thermal properties, experimental, pore } \\
\text { water chemistry, statistical model evaluation }\end{array}$ \\
\hline & \multicolumn{2}{|l}{ Royal Military College of Canada } \\
\hline
\end{tabular}




\title{
THERMAL PROPERTIES OF ENGINEERED BARRIERS FOR A CANADIAN DEEP GEOLOGICAL REPOSITORY
}

\author{
Abootalebi, Pedram \\ Research Associate \\ (former Queen's University graduate student) \\ Royal Military College of Canada \\ Kingston, Ontario, K7K 7B4 \\ Siemens, Greg (Corresponding Author) \\ Professor and Research Director \\ GeoEngineering Centre at Queen's-RMC \\ Department of Civil Engineering \\ Royal Military College of Canada \\ Kingston, Ontario, K7K 7B4, CANADA \\ e: siemens@rmc.ca; p: +1-613-541-6000x6396;
}

\begin{abstract}
Global energy needs continue to rise along with society's desire for carbon-reduced energy sources to limit climate change effects. One viable carbon-reduced energy source is nuclear power, which provides more than half the electricity requirements of the province of Ontario. Within Canada there are more than 2.5 million bundles of spent nuclear fuel, which will be stored in a deep geological repository. Efficiency of the repository system depends on dissipation of thermal energy. A comprehensive experimental study is reported on thermal properties of barrier materials. The influence of bentonite type, variability, moisture, and temperature on thermal properties are examined. Results show strong influence of moisture on thermal properties, some influence of temperature on low density bentonite, minor influence of bentonite type as well as low variability in the experimental measurements. The extensive database of physical measurements is compared with values from the literature and then used to statistically evaluate thermal property models selected from the literature. Using the base parameters from the literature, thermal property models performed adequately, however, soil-specific calibration of the model inputs improved the fit significantly. These results are now available to perform the numerical models for the proposed Canadian deep geologic repository for used nuclear fuel.
\end{abstract}

Keywords: deep geologic repository, bentonite, thermal properties, experimental, pore water chemistry, statistical model evaluation 


\section{INTRODUCTION}

Global energy needs continue to rise along with society's desire for carbon-reduced energy sources to limit climate change effects. One viable carbon-reduced energy source is nuclear power. More than half of the electricity requirements of the province of Ontario, Canada (population $=13$ million) are met by nuclear power. Along with the efficiency, safety, carbon-reduction, and reliability benefits of nuclear power in Canada comes the ethical and environmental responsibility to safely care for the waste products. Within Canada there are more than 2.5 million bundles of spent nuclear fuel with another approximately 2 million bundles to be generated in the future (Garamszeghy 2015). Canada, and every country around the world who has come to the decision on a long-term solution for nuclear waste, has chosen long-term burial in a deep geological repository. A deep geological repository (Figure 1) consists of a network of placement rooms at depth where used fuel containers will be surrounded by an engineered barrier system. The engineered materials include bentonite for its properties of low permeability, high swelling potential, and durability in the presence of high temperatures and aggressive chemical environments. A deep geological repository will be subjected to complex thermal-hydraulicmechanical-chemical-biological conditions as the waste products will be placed at an elevated temperature during construction and the surrounding groundwater chemistry will likely have elevated salinity. The performance of the repository must be evaluated for this complex set of conditions to ensure isolation of the waste products. To construct a representative model, accurate and reliable material properties for all components of the repository are required. Thus, since 1980s jurisdictions in charge of nuclear waste management have been characterizing potential sealing materials as well as the host rock by performing full-scale and laboratory tests.

Countries around the world have considered various barrier material compositions based on their specific waste, geologic conditions, and available supply. In view of the required properties of the sealing materials, Pusch (1979) suggested the use of high density bentonite blocks, which can meet the 
design requirements of the barrier system. Both cement-based and bentonite-based barriers are considered, however, most are proposing the use of bentonite rather than cement (ANDRA, France; ENRESA, Spain). In addition, some countries include a mixture of aggregate with either expansive or non-expansive clay as the sealing component. Several materials have been proposed including: crushed granite and sand (NWMO, Canada), crushed basalt (DOE, United States of America), zeolytes and quartz (JNC, Japan), quartz and graphite (ANDRA France; ONDRAF/NIRAS, Belgium) as aggregates. Adding coarse crystalline particles to materials improves thermal properties of bentonite, increases the mechanical resistance of the compacted blocks, and reduces costs (Villar 2002). Furthermore, to increase constructability, some studies have examined using high density bentonite pellets combined with powdered bentonite as an engineered barrier (Salo and Kukkola 1989; Volckaert et al. 1996). This combination creates a dual porosity material that could have advantageous properties. Thus, engineered barrier systems for proposed deep geological repositories include a number of unique materials that must be characterized.

Amongst other design aspects, the engineered barriers will transfer the thermal energy from the spent nuclear fuel to the surrounding geosphere. Therefore, the thermal properties of the engineered barriers are a key attribute of the system in terms of efficiency and size of the repository. The environment will likely include competing gradients of groundwater pressure driving moisture into the repository and thermal gradients driving moisture away from the used fuel container as the waste continues to decay. Over their lifetime, the engineered barriers will be at variable saturation levels and temperatures. It is necessary to determine thermal properties of engineered barriers over a wide range of moisture contents (degree of saturations) and variable temperatures $\left(25^{\circ} \mathrm{C}\right.$ and $\left.80^{\circ} \mathrm{C}\right)$. With respect to the Canadian concept, a key design criterion of the repository is the maximum surface temperature of the used fuel container must be below $100^{\circ} \mathrm{C}$ (Maak 2006). Therefore, the efficiency with which the barrier materials transfer heat energy to the surrounding geosphere is a critical aspect of the performance of the repository. 
Thermal properties of barriers may be evaluated by laboratory experiments or preliminary estimations using suggested values from the literature. Several experimental studies have examined the thermal behavior of geo-materials over different conditions including material composition, dry density, saturation, and temperature (Coulon et al. 1987; Beziat et al. 1988; Radhakrisha et al. 1989; Suzuki et al. 1992; Borgensson et al. 1994; Graham et al. 1997; Madsen 1998; Villar 2002; Ould-Lahoucine et al. 2002; Engelhardt and Finsterle 2003; Tang et al. 2008; Ye et al. 2010; Man et al. 2011; Kim et al. 2012; Likos 2014; Lee et al. 2016). Baumgartner et al. (2006) estimated the thermal conductivity and specific heat capacity of bentonite materials based on their composition and density. Estimations consisted of a series of sinusoidal curves for thermal conductivity and specific heat capacity as a function of degree of saturation. Barry-Macaulay et al. (2015) and Tang et al. (2008) reviewed an extensive number of thermal conductivity predictions and evaluated selected thermal conductivity models (Johansen 1975; Cote and Konrad 2005; Lu et al. 2007; Sakashita and Kumada 1998; among others). Both papers noted the correlation between quartz content and thermal conductivity. Barry-Macaulay et al. (2015) also suggested that existing models may be improved upon using soil-specific calibration of the model inputs. Tang et al. (2008) examined bentonite thermal data and found that thermal conductivity varied linearly with the volume fraction of air. Ideally thermal models for numerical models for deep geologic repositories would have an experimental basis, which is used to calibrate thermal conductivity constitutive models.

Additional Canadian considerations are a decision on the bentonite source to be used in the repository and the exact location, which will influence porewater chemistry of the groundwater. There are two potential bentonite sources, which are MX80 and National Standard. These bentonites are naturally occurring materials and their properties may vary spatially in nature. Once the deep geological repository is under construction, commercial bentonite will be received at the facility over a 30 -year period and the material properties will need to meet performance requirements throughout construction. In Canada, much of the previous laboratory work on Wyoming bentonite properties was carried out on a 
limited number of shipments, and there is a need to develop a larger database. Moreover, the focus of previous work has been largely on saturated bentonite. In Canada, the exact site of the repository is still unknown and therefore the precise geological conditions of the repository are potentially variable. From a hydraulic perspective, the quantity and type of groundwater infiltration into the repository will be governed by the local and regional rock type, fracture network, and pore pressure conditions. Theoretically there is a potential for limited infiltration during the thermally transient phase of the repository, which would allow significant drying of the sealing materials. The need to measure bentonite properties for a wide range of temperature, moisture, and porewater chemistry conditions is clear.

The purpose of this paper is to provide a database of material properties, mainly focused on thermal properties, of sealing materials to support Canada's concept for a deep geological repository, to compare the results with predicted values and to examine the variability within the results. A comprehensive study examining the effect of bentonite type and porewater chemistry on index properties as well as degree of saturation and temperature on thermal properties of high and low-density bentonite materials is currently unavailable in the literature in particular for the unique highly saline groundwater conditions that could be encountered in a Canadian sedimentary rock geosphere. Additionally, results will be compared with selected thermal conductivity results and selected models to assess model applicability for barrier materials. The results from this study are directly applicable to provide information on the performance of sealing materials over a wide range of thermal, hydraulic and chemical environments.

\section{MATERIALS AND METHODS}

\section{Materials}

The materials examined in this study are proposed to be used in the deep geologic repository (NWMO 2015) and include highly compacted bentonite, gapfill, and dense backfill (Figure 1). Highly compacted bentonite and gapfill materials were prepared using two different bentonite sources. 
Compacted samples were prepared with two mixing fluids, which are distilled water and a synthetic porewater for sedimentary formations. Material properties are described in this section and summarized in Table 1, Table 2, Figure 2 and Figure 3.

1. Highly compacted bentonite, which is located next to the used fuel container, is composed of bentonite clay compacted to a minimum dry density of $1.7 \mathrm{~g} / \mathrm{cm}^{3}$. Highly compacted bentonite samples were prepared using either VOLCLAY MX80 - manufactured by American Colloid Company or National Standard - manufactured by Bentonite Performance Minerals LLC. Index properties of the two bentonites, listed in Table 2, indicate both bentonites have high montmorillonite content and are classified as high plasticity clay. The swell index (ASTM D5890) and solution retention capacity (Lee et al. 2005, Figure 3) are also typical of bentonitic materials. The effect of the saline porewater on index properties was to lower the liquid limit, swell index, and solution retention capacity significantly in both bentonites.

2. Gapfill, which is placed as fill between the compacted blocks and the insitu rock (Figure 1), is composed of bentonite pellets compacted to a minimum dry density of $2.12 \mathrm{~g} / \mathrm{cm}^{3}$ with a grain-size distribution defined in Figure 2a. The maximum allowable pellet size is $8 \mathrm{~mm}$ (photograph in Figure 2a) while the average overall dry density of gapfill will be $1.41 \mathrm{~g} / \mathrm{cm}^{3}$. Gapfill for this study was prepared using one of two methods, which depended on the bentonite type. Gapfill composed of National Standard bentonite was manufactured by NAGRA of Switzerland and provided by NWMO. Gapfill composed of MX80 bentonite was manufactured by compacting $150 \mathrm{~mm}$ diameter by $50 \mathrm{~mm}$ tall pucks to the target dry density, crushing them, and then sieving the crushed pellets to the required grain-size (Figure 2a).

3. Dense backfill, which is a spacer between adjacent highly compacted bentonite blocks (Figure 1), is composed of $70 \%$ crushed granite (grain-size envelope in Figure $2 \mathrm{~b}$ ), $25 \%$ clay and $5 \%$ bentonite compacted to a minimum dry density of $2.12 \mathrm{~g} / \mathrm{cm}^{3}$. Crushed Lac du 
Bonnet Granite from Cold Spring Granite (Canada) Ltd, B-Clay from Plainsman Clays Ltd. And MX80 bentonite were used in this study.

\section{Materials Preparation}

Specimens were prepared using a process based on Martino et al. (2011) to achieve reliable and consistent moisture equilibrium. The constituents (Table 1) are placed in an oven at $105^{\circ} \mathrm{C}$ for at least 24 hours. The material is removed from the oven, sealed, and allowed to come to thermal equilibrium with the laboratory. The required quantity of each constituent is removed and placed in a mixing bowl. Wetting agent is added to the sample via misting with a spray bottle to achieve the target moisture content. Following mixing (20 min for each batch), the soil is placed within two sealed bags and in a fridge for at least 48 hours for moisture equilibrium. Each weekday the soil is mixed inside the bag to encourage moisture equilibrium.

Static compaction was selected for thermal property sample preparation as it results in a specimen with uniform density over a wide range of moisture content (Radhakrishna et al. 1989). A strain-based criterion is used. Compaction is performed using a General Electric 30,000 lb (130 kN) electromatic universal testing machine. For highly compacted bentonite and dense backfill, each layer is over compressed for a 10-second interval such that the specimen rebounds to the target height. Gapfill is not over compressed due to its lower density. Figure 4 displays the high compression loads required for highly compacted bentonite and dense backfill as a function of degree of saturation. Compaction pressure is a minimum at $100 \%$ saturation for all materials and increases for lower moisture contents. The maximum compression pressure was $45 \mathrm{MPa}$ for highly compacted bentonite comprised of National Standard. Somewhat lower compaction effort is required for highly compacted bentonite samples made from MX80 due to a wider range of grain-sizes as opposed to National Standard bentonite, which is in powder form. With respect to the dense backfill compaction force, it requires lower compaction pressure at high saturation degrees compared to highly compacted bentonite, but as specimen dries compaction pressure increases considerably to $22 \mathrm{MPa}$ at degree of saturation of $0 \%$. 


\section{Salt Solution Preparation}

The groundwater chemistry of the insitu rock in which the deep geologic repository is located will impact the design and performance of the repository. In Canada, the potential host rocks for the proposed deep geologic repository are either likely crystalline or sedimentary. In this study, the reference sedimentary rock saline water representing limestone (SR-L-2013) is used. The composition of SR-L-2013 is listed in Table 3 with the total dissolved solids (TDS) equalling 223.4 g/L. Precise procedures were followed to prepare the reference water solution. Three samples from each solution were taken to confirm solution density and TDS.

Two test methods were used to complete compaction testing of materials in this study. For dense backfill, traditional Modified Proctor tests were performed in accordance with ASTM D1557. For the two sources of bentonite, Dixon et al. (1985) developed a test method, which obtained a high coefficient of correlation to Modified Proctor $\left(\mathrm{R}^{2}>98 \%\right)$, and uses significantly less bentonite for each specimen. In this method, $31.5 \mathrm{~mm}$ tall by $31.5 \mathrm{~mm}$ diameter specimens are compacted in one layer via using 8 dynamic drops of the Modified Proctor compaction hammer. Benefits of the method are a reduction of both materials and preparation time. The reduction of materials use and preparation allow for more tests to be performed and the compaction curves to be better defined.

\section{Thermal Property Device and Test Procedures}

A comprehensive experimental program was undertaken to assess the effect of bentonite type, temperature, and degree of saturation on the thermal properties of highly compacted bentonite, gapfill and dense backfill. Samples were prepared using distilled water at degree of saturation values ranging from

$0-100 \%$ at room temperature and four (4) degree of saturation values at $80^{\circ} \mathrm{C}$ with at least three specimens at each moisture condition to evaluate variability of the properties.

Methods for measuring thermal conductivity include both steady-state and transient options. Yao and Likos (2017) reviewed transient plane and line source thermal conductivity methods investigating 
the effect of measurement method, saturation, and soil type. Two of the most common devices are the needle probe (Originally developed by De Vries and Peck 1958; Von Herzen and Maxwell 1959) and the divided-bar apparatus (Originally developed by Benfield 1939; Bullard 1939). Thermal property apparatuses continue to be developed including photoacoustic spectroscopy (Schmitt et al 2017) and concurrent unsaturated and thermal property measurements (Dong et al. 2014; Yao et al. 2014). Improvements to thermal devices include transient measurements using the divided-bar apparatus (Pasquale et al. 2015), low-cost divided-bar apparatus (McGuinness et al. 2014), assessing the impact of water migration on thermal measurements (Woodward et al. 2013), use of thermal imaging (Kodikara et al. 2011), and a thermal cell for measuring thermal conductivity of geosynthetic clay liners (Ali et al. 2016). Another more recent option, which is used in this study, is the Hot Disk Thermal Constants Analyser (Hot Disk 2014). This test is based on a Transient Plane Source Technology, which allows for measurement of thermal conductivity, thermal diffusivity as well as volumetric heat capacity during a single test. This technology has been successfully used for measuring thermal properties of compacted bentonite (Ye et al. 2010; Lee et al. 2016). The method provides efficient and accurate thermal property measurements at laboratory and elevated temperatures as well as flexibility to test brittle samples in the compaction mould (see one-sided method below).

The thermal property measurement method uses a transiently heated planar sensor (Figure 5a), which consists of an electrical conducting pattern in a shape of double spiral etched out of the thin sheet of nickel. Covering both sides of the sensor are thin sheets of an insulating material (Kapton). When carrying out a measurement, the sensor is both a heat source and a dynamic temperature sensor. He (2005) provides the theoretical background for analysis of the test results and a summary is given here. Analysis solves the heat conduction differential equation for an isotropic material with temperature independent thermal conductivity, which is:

$$
\frac{\delta^{2} \mathrm{~T}}{\delta \mathrm{x}^{2}}+\frac{\delta^{2} \mathrm{~T}}{\delta \mathrm{y}^{2}}+\frac{\delta^{2} \mathrm{~T}}{\delta \mathrm{z}^{2}}=\frac{1}{\kappa} \frac{\delta \mathrm{T}}{\delta \mathrm{t}}
$$


where $\mathrm{T}=$ temperature, $\mathrm{x}, \mathrm{y}, \mathrm{z}=$ cartesian coordinates, $\mathrm{\kappa}=$ thermal diffusivity and $\mathrm{t}=$ time. Thermal properties are related by the following equation:

$$
\lambda=\mathrm{C} \rho \kappa
$$

where $\lambda$ is thermal conductivity, $\mathrm{C}$ is specific heat capacity, and $\rho$ is density. Assumptions of the analysis include the heat source is a series of concentric circles and the sensor is located within an infinite medium. To ensure the infinite medium assumption is valid, the heat pulse probing depth is checked against the size of the specimen. The probing depth, $\Delta \mathrm{p}$, is calculated as:

$$
\Delta \mathrm{p}=2 \sqrt{\kappa \mathrm{t}}
$$

Valid tests have the probing depth $(\Delta \mathrm{p})$ to be less than the nearest specimen boundary, which is the minimum of the distance from the outer edge of the sensor to the boundary of the specimen in both the horizontal or vertical directions.

The sensor applies a constant power to the specimen and measures the incurred temperature change as the resistance across the circuit. Resistance across the circuit as a function of time, $\mathrm{R}(\mathrm{t})$, is:

$$
\mathrm{R}(\mathrm{t})=\mathrm{R}_{0}\left\{1+\alpha\left[\Delta \mathrm{T}_{\mathrm{i}}+\Delta \mathrm{T}_{\mathrm{avg}}(\tau)\right]\right\}
$$

where $\mathrm{R}_{0}$ is the resistance of the disk prior to heating $(\mathrm{t}=0)$, $\alpha$ is the temperature coefficient of resistivity of nickel, $\Delta \mathrm{T}_{\mathrm{i}}$ is the constant temperature difference that develops across the sensor insulation, and $\Delta \mathrm{T}_{\mathrm{avg}}(\tau)$ is the average temperature increase of the specimen surface in contact with the sensor surface. Solving for the total temperature change gives:

$$
\Delta \mathrm{T}_{\mathrm{i}}+\Delta \mathrm{T}_{\mathrm{avg}}(\tau)=\left(\frac{1}{\alpha}\right)\left\{\left[\frac{\mathrm{R}(\mathrm{t})}{\mathrm{R}_{0}}\right]-1\right\}
$$

The temperature difference across the sensor's insulating layer $\left(\Delta \mathrm{T}_{\mathrm{i}}\right)$, which becomes constant over a short period of time, is calculated as:

$$
\Delta \mathrm{T}_{\mathrm{i}}=\left(\frac{\delta^{2}}{\kappa_{\mathrm{j}}}\right)
$$


where $\delta$ is the thickness of the insulating material and $\kappa_{\mathrm{j}}$ is the thermal diffusivity of the insulating material. Temperature increase of the soil is:

$$
\Delta \mathrm{T}_{\mathrm{i}}(\tau)=\left(\frac{\mathrm{P}_{0}}{\pi^{3 / 2} \mathrm{a} \lambda}\right) \mathrm{D}(\tau)
$$

where $\mathrm{P}_{0}$ is power output of hot disk sensor, a is the overall radius of the disk, and $\mathrm{D}(\tau)$ is the dimensionless time dependent function. The dimensionless time dependent function is given as:

$$
\tau=\sqrt{\mathrm{t} / \theta}=\frac{\sqrt{\kappa \mathrm{t}}}{\mathrm{a}}
$$

where $\theta$ is the characteristic time. $\Delta \mathrm{T}(\tau)$ is plotted as function of $\mathrm{D}(\tau)$, which is a straight line. From slope of that line, thermal conductivity of the sample can be calculated. However, the correct value of $\tau$ is generally unknown since it is related to thermal diffusivity of the sample. Thus, the final straight line from which the thermal conductivity is calculated is obtained through an iterative process.

The details behind thermal property interpretation can be found in He (2005). A typical thermal property test (Figure 5d) is plotted as temperature increase versus time. The initial temperature increase arises from the insulation material of the sensor and contact resistance between sensor and sample. Thus, data from linear part of graph is selected for analysis of the soil's thermal properties. One experimental detail is that the diameter of sensor should be at least twice of maximum grain size of the sample (Hot Disk 2014). The Hot Disk Sensor 8563, with diameter of $19.816 \mathrm{~mm}$ was selected, which satisfies the grain-size requirement for the bentonitic materials with minor non-compliance of dense backfill (Figure 2 shows that $<10 \%$ of the granite component are $<7 \%$ overall have diameter greater than $10 \mathrm{~mm}$ ).

The range of moisture contents of the tests necessitates two types of tests. Wetter specimens could be removed from the compaction mould in an undisturbed manner. For wetter specimens, two circular discs are prepared and the sensor is secured between the discs as depicted in Figure 5b. Drier specimens were brittle and had to be tested within the compaction mould as shown in Figure 5c. The procedures for each test are: 
1. A two-sided test (Figure 5b) is performed on compacted specimens that can be removed from the compaction mould in an undisturbed manner, which includes all highly compacted bentonite samples and dense backfill specimens with $\mathrm{Sr}>60 \%$. Specimens are prepared by compacting two adjacent cylindrical pucks in three-split mould. The size of the puck is related to the maximum grain size and homogeneity of the sample. During compaction, a piece of plastic wrap is placed between the pucks to allow them to be separated for thermal testing. This type of test is termed a 'two-sided test' as the thermal conductivity sensor is placed between two specimens (Figure 5b). The size of the thermal property specimens depends on the maximum grain-size of the constituent materials. For highly compacted bentonite material, two $50 \mathrm{~mm}$-diameter by 20 - $\mathrm{mm}$ pucks are compacted for each two-sided test. For dense backfill, due to the presence of crushed granite (up to $\sim 10 \mathrm{~mm}$ diameter) a 75 mm-diameter split mould is used to make the $30 \mathrm{~mm}$ tall pucks. After placing the thermal property sensor between the compacted pucks in sample holder a metal disk is located on the top of the pucks. Contact between the sensor and the pucks is ensured by applying a nominal force through the test frame (Figure 5a). Finally, a lid is placed over the apparatus to minimize heat loss during thermal property tests.

2. A one-sided test (Figure 5c) is performed on compacted specimens that would be disturbed during removal from the compaction mould, which includes all gapfill and drier dense backfill $(\mathrm{Sr}<60 \%)$ specimens. The $75 \mathrm{~mm}$ diameter compaction mould has a slit cut into the side of the mould at $30 \mathrm{~mm}$ height to allow for placement of the thermal conductivity sensor on the top face of the compacted specimen. During compaction, the slit is covered to avoid soil spillage and loss of confinement. During thermal testing, a block of insulation is placed on top of the specimen to limit thermal energy loss. Since some thermal energy loss could occur through the insulation, the thermal properties are measured and used as an input for thermal property calculation. A normal stress is applied to ensure contact between the sensor 
and the specimen. To confirm that both methods were providing reliable measurements, several tests using both methods were performed on stainless steel pucks, which have welldefined thermal properties. The results for one-sided and two-sided tests on stainless steel pucks deviated less than $2 \%$ giving confidence in the test protocols.

Thermal property tests at $80^{\circ} \mathrm{C}$ were performed using a similar methodology as the laboratory temperature tests. The only differences were replacement of the sensor cable with one that was rated for elevated temperature and extra precautions to limit moisture loss during thermal equilibrium. Both the one-sided and two-sided test apparatuses were placed within a sealed plastic bag. A hole for the sensor wire was sealed with Tuck tape. The two-sided test pucks were wrapped with at least 5 layers of plastic wrap prior to testing. The insulation placed on top of the one-sided test as well as the slit in the mould were sealed with additional plastic wrap. The wrapped apparatuses were placed in an oven alongside a bowl of water in order to maintain high relative humidity within the oven. Thermal property measurements are taken after the specimen achieves thermal equilibrium with the environment as plotted in Figure 5e. Temperature drift just prior to six (6) thermal property tests for a single specimen. After 30 minutes in the $80^{\circ} \mathrm{C}$ environment temperature drift was $8 \mathrm{mK} / \mathrm{s}$, while after $330 \mathrm{~min}$ temperature drift decreased to $0.3 \mathrm{mK} / \mathrm{s}$, which is consistent with thermal equilibrium. To confirm that insignificant moisture loss occurs during $80^{\circ} \mathrm{C}$ tests moisture content of each specimen is measured in three ways: 1. from leftover prepared soil, 2. drying the sample after thermal property measurement, and 3. from the difference in weight of the test apparatus and sample before and after the thermal property measurement. Less than 5\% decrease in degree of saturation was observed for highly compacted bentonite and gapfill tests performed at $80^{\circ} \mathrm{C}$. Dense backfill materials desaturated at most $10 \%$ at high moisture contents. All results are plotted versus degree of saturation measured after the test. In some near-saturated samples small shrinkage cracks appeared on the perimeter of the samples. In these samples, the acceptable probing depth was the distance from the sensor to the crack. 


\section{RESULTS}

In this section results for compaction tests as well as experimentally measured thermal properties are presented. The effect of porewater chemistry on compaction properties and the effect of degree of saturation and temperature on thermal properties is examined. Of note, in this study, each test has been repeated at least three times to evaluate of variability of materials.

\section{Compaction}

Results for compaction of MX80 bentonite, National Standard bentonite and dense backfill are plotted in Figure 6 as dry density versus water content. For tests completed using saline pore water results are plotted for both bulk water content $\left(\mathrm{w}=\mathrm{M}_{\mathrm{water}} /\left[\mathrm{M}_{\text {soil }}+\mathrm{M}_{\text {salt }}\right]\right)$ and solution water content $\left(\mathrm{w}_{\mathrm{l}}=\left[\mathrm{M}_{\mathrm{water}}+\mathrm{M}_{\text {salt }}\right] / \mathrm{M}_{\text {soil }}\right)$.

Compaction results on MX80 bentonite for distilled water and SR-L-2013 are given in Figure 6a. Fourty-three (43) compaction points for MX80 bentonite were tested using distilled water as pore fluid and twenty-eight (28) points with the characteristic sedimentary rock porewater solution (SR-L-2013). Comparing results for distilled water and saline solution against solution water content, both have similar compaction outcomes for the energy imparted during the test. When the saline results are plotted in terms of bulk water content, MX80 bentonite shows sensitivity to the saline environment. The maximum density of $1.81 \mathrm{~g} / \mathrm{cm}^{3}$ at optimum water content of $19.5 \%$ for distilled water increases to 1.87 $\mathrm{g} / \mathrm{cm}^{3}$ at $15.3 \%$ bulk water content for the saline porewater.

Figure $6 \mathrm{~b}$ plots results for National Standard bentonite. In this case, 28 compaction points were performed for both water compositions. The compaction curve of National Standard with distilled water is flat indicating a low sensitivity of dry density to water content. The average dry density is 1.68-1.69 $\mathrm{g} / \mathrm{cm}^{3}$ over the range of $3-25 \%$ water content. Compaction with saline porewater does show sensitivity to water content with an upward trend to $1.82 \mathrm{~g} / \mathrm{cm}^{3}$ at bulk water content $18 \%$.

Modified compaction tests on dense backfill are plotted on Figure 6c. Results for both distilled water and solution water content are comparable with maximum dry density of $2.20 \mathrm{~g} / \mathrm{cm}^{3}$ measured at 
$6 \%$ water content. Moderate sensitivity is noted in the bulk water content results with a maximum dry density of $2.23 \mathrm{~g} / \mathrm{cm}^{3}$ at $5.8 \%$.

\section{Thermal Properties}

Measured thermal conductivity and volumetric heat capacity are plotted versus degree of saturation for highly compacted bentonite $\left(42\right.$ measurements at $25^{\circ} \mathrm{C}$ and 12 at $80^{\circ} \mathrm{C}$ for $\mathrm{MX} 80$ and 36 measurements at $25^{\circ} \mathrm{C}$ and 15 at $80^{\circ} \mathrm{C}$ for National Standard), gapfill (33 measurements at $25^{\circ} \mathrm{C}$ and 12 at $80^{\circ} \mathrm{C}$ for MX80 and 40 measurements at $25^{\circ} \mathrm{C}$ and 16 at $80^{\circ} \mathrm{C}$ for National Standard), and dense backfill (45 measurements at $25^{\circ} \mathrm{C}$ and 15 at $80^{\circ} \mathrm{C}$ ) in Figure 7, Figure 8, and Figure 9. Figure 7 summarizes the results for highly compacted bentonite for both bentonite types of bentonites at $25^{\circ} \mathrm{C}$ and $80^{\circ} \mathrm{C}$. Good repeatability is noted in both thermal conductivity and volumetric heat capacity from 0 $100 \%$ saturation. Comparing the $\mathrm{Sr}=0 \%$ and $\mathrm{Sr}=100 \%$ data indicates a 2.8 -fold increase in thermal conductivity and 2.8 -fold increase in volumetric heat capacity from dry to saturated. At $80^{\circ} \mathrm{C}$, thermal conductivity of MX80 specimens increases $10 \%$ between $\mathrm{Sr}=10-80 \%$. At $\mathrm{Sr}=0$ and $\mathrm{Sr}=100 \%$ the temperature effect is nil. For National Standard bentonite specimens, increasing temperature by $60^{\circ} \mathrm{C}$ does not affect thermal conductivity of highly compacted bentonite. Whereas the slope of the volumetric heat capacity increases $25 \%$ more at $80^{\circ} \mathrm{C}$ compared to room temperature for National Standard bentonite.

With respect to the gapfill (Figure 8), thermal conductivity results are internally consistent over a wide range of moisture content with 3-4-fold increase from dry to saturated condition. Notable is that little increase in thermal conductivity occurs from degree of saturation from $0 \%$ to $20 \%$. This is consistent with the Boltzmann sigmoidal curve predicted by Baumgartner (2006). Because of dual porosity and dispersity of particles of the gapfill, results of volumetric specific heat capacity display relatively more variability. Thermal conductivity of gapfill rises about $15-30 \%$ at $80^{\circ} \mathrm{C}$ with more increase at higher moisture contents. This trend mainly stems from higher air void fraction and water void fraction of gapfill material compared to highly compacted bentonite. Thus, higher movement of 
fluid phase results in transporting heat better, thereby increasing the apparent thermal conductivity (Beziat et al. 1988). Volumetric specific heat capacity of gapfill material increased between 2-35\% due an increase in temperature from $25-80^{\circ} \mathrm{C}$.

Figure 9 plots results for dense backfill material including thermal conductivity and volumetric heat capacity. Thermal conductivity changes from $0.85 \mathrm{~W} / \mathrm{m} . \mathrm{K}$ at $\mathrm{Sr}=0 \%$ to $2.2 \mathrm{~W} / \mathrm{m} . \mathrm{K}$ at $\mathrm{Sr}=100 \%$. Heterogeneity of dense backfill materials due to the various grain-sizes incorporated into the mixture is the main reason of more scatter in the results compared to $100 \%$ bentonite materials. Fluctuation of volumetric heat capacity results at specified saturation signifies more than thermal conductivity. Differences between the $25^{\circ} \mathrm{C}$ and $80^{\circ} \mathrm{C}$ measurements of both thermal conductivity and volumetric heat capacity are insignificant.

\section{DISCUSSION}

The material properties reported in this study are affected by their constituent materials, moisture content, porewater salinity, and inherent variability in the source materials. In this section, the influence of these controlling factors on the results will be examined and the thermal properties will be compared with values from the literature as well as predictive models for thermal conductivity.

\section{Influence of Bentonite Type and Porewater Chemistry on Compaction}

Notable trends are observed in the compaction (Figure 6) and index properties (Table 2) results, which concur with the distinctive properties of the constituent materials and porewater chemistry. The results from this section can be used as background information on anticipated properties that would be encountered during construction of a deep geologic repository. The information is useful to direct Quality Assurance / Quality Control guidelines in terms of anticipated variability in these properties. Comparing the two bentonite types on compaction of highly compacted bentonite shows that higher modified optimum dry density is measured in the MX80 compared with National Standard. This is likely due to the granular nature of the MX80 as opposed to the finer powder of the National Standard. 
Considering the influence of porewater salinity indicates that optimum density increases by $0.4 \mathrm{~g} / \mathrm{cm}^{3}$ for National Standard compared to $0.7 \mathrm{~g} / \mathrm{cm}^{3}$ for MX80. The increase in salinity of the pore fluid causes a decrease in the diffuse double layer thickness (Mitchell 1976) and allows for an increase in the optimum density. Other measured values for optimum density of highly compacted bentonite composed of National Standard and MX80 were reported by Priyanto et al. (2013 (unpublished report), $1.61 \mathrm{~g} / \mathrm{cm}^{3}$ ) and Golder (2013 (unpublished report) $1.66 \mathrm{~g} / \mathrm{cm}^{3}$ ) respectively. The optimum density of $1.69 \mathrm{~g} / \mathrm{cm}^{3}$ and $1.81 \mathrm{~g} / \mathrm{cm}^{3}$ for National Standard and MX80 respectively achieved in this study indicates some minor variability in the measurements as well as comparability of results from three different laboratories.

\section{Influence of Bentonite Type, Degree of Saturation and Temperature on Thermal}

\section{Properties}

Thermal properties of geo-materials are a function of their constituents, moisture content, dry density, and temperature. Fitted curves for highly compacted bentonite, gapfill, and dense backfill for thermal conductivity and volumetric heat capacity, plotted in Figure 10, show increase in thermal properties with increasing saturation. The reason is the replacement of air (conductivity $=0.025 \mathrm{~W} / \mathrm{m} . \mathrm{K}$ ) with water (conductivity $=0.57 \mathrm{~W} / \mathrm{m} . \mathrm{K}$ ) within the pore volume from $0-100 \%$ saturation. Analyzing the influence of bentonite type on thermal conductivity of highly compacted bentonite (Figure 10a and 10b) shows comparable results for the National Standard and $\mathrm{MX} 80$ results at $25^{\circ} \mathrm{C}$ and $80^{\circ} \mathrm{C}$. Both types show linear increase in thermal conductivity over the range of possible moisture contents $(0<\mathrm{Sr}<100 \%)$. Thermal conductivity of highly compacted bentonite shows no influence of temperature for dry and saturated tests. Highly compacted bentonite composed of MX80 shows nominal more sensitivity to temperature compared with National Standard over the $\mathrm{Sr}=20-50 \%$ range, which is likely due to variability. For volumetric heat capacity, the influence of bentonite type is less than variability of the measurements.

The gapfill results display the influence of dry density and the pelletized nature of the constituent material compared with highly compacted bentonite. Only minor differences due to bentonite type are 
noted for gapfill. Thermal conductivity of gapfill is lower than highly compacted bentonite for the entire range of saturation due to the lower overall density. Thermal conductivity of gapfill is non-linear versus degree of saturation (sigmoidal curve) as opposed to the linear behavior observed in highly compacted bentonite. In gapfill, only minor increase in thermal conductivity occurs from $0-20 \%$ saturation followed by a relatively linear increase from 20-100\%. Gapfill, which is composed of a mixture of high density pellets $\left(2.12 \mathrm{~g} / \mathrm{cm}^{3}\right)$ and finer grain-sizes as shown on Figure 2, has a more significant non-uniform distribution of water content in the low range compared with most unsaturated soils. Water preferentially hydrates the bentonite powder as well as the surface of the pellets, leaving the inside of the pellets dry. The larger dry pellets govern the thermal properties rather than the matrix of slightly hydrated powder at saturations less than $20 \%$. With a disconnected water phase resulting from the minimal amount of water as well as the internally dry pellets, little increase in overall thermal conductivity occurs until the water phase becomes connected at $20 \%$ saturation. Thermal conductivity of gapfill increases in $15-30 \%$ due to the $55^{\circ} \mathrm{C}$ increase in temperature. Gapfill's lower density, $1.4 \mathrm{~g} / \mathrm{cm}^{3}$ compared with $1.7 \mathrm{~g} / \mathrm{cm}^{3}$ for highly compacted bentonite, leads to an increased influence from the properties of air and water. Over the temperature range of $20-80^{\circ} \mathrm{C}$, air and water's thermal conductivity changes by $15 \%$ and $10 \%$ respectively (Engineering ToolBox 2017). This increase in component thermal conductivity is reflected in the gapfill thermal property results.

Dense backfill, composed of $70 \%$ crushed granite shows a significantly higher thermal conductivity relative to the $100 \%$ bentonite materials. The increase ranges from $0.35-1.0 \mathrm{~W} / \mathrm{m} . \mathrm{K}$ over the range of $0-100 \%$ saturation. Dense backfill also shows sensitivity in the volumetric heat capacity results due to its composition. With just $25 \%$ clayey materials and $70 \%$ crushed granite, the volumetric heat capacity results show more scatter than the $100 \%$ bentonite materials. This is due to either the inherent heterogeneities within dense backfill or the larger particles $(>10 \mathrm{~mm})$ being in close proximity to the sensor and influencing the results. Nonetheless, the overall trends in the thermal property data is consistent. 


\section{Comparison of Bentonite Thermal Conductivity with Previous Studies}

A number of studies have examined the thermal properties of bentonite materials from around the world. The bentonite thermal conductivity results reported here for National Standard and MX80 bentonite for highly compacted bentonite and gapfill at $25^{\circ} \mathrm{C}$ are plotted in Figure 11 along with data reported in the literature including FEBEX (Villar 2002), GMZ (Ye et al. 2010), Kunigel (Suzuki et al. 1992), Kyeongju (Lee et al. 2016), and MX80 (Tang et al. 2008). The data are grouped by bentonite type and dry density. The results show thermal conductivity generally increasing with degree of saturation and dry density as anticipated. Across bentonite types, thermal conductivity is relatively consistent, however, variation is noted for all measurements. With this notable variation, interpreting general trends across bentonite types is complicated. At degree of saturation above $40 \%$, the relationship between thermal conductivity and degree of saturation becomes linear. The effect of high quartz content is visually apparent in the Kunigel bentonite, which consists of $29-38 \%$ quartz by mass. The high thermal conductivity of quartz $(7.7 \mathrm{~W} / \mathrm{m} . \mathrm{K})$ dominates over other minerals $(\sim 2.0 \mathrm{~W} / \mathrm{m} . \mathrm{K})$. Thermal conductivity models following on Johansen (1975) including Cote and Konrad (2005), Balland and Arp (2005), and Lu et al. (2007) follow this principle in their development.

\section{Statistical Comparison of Thermal Properties with Baumgartner 2006}

Baumgartner (2006) introduced family of curves for predicting thermal conductivity of highly compacted bentonite. By doing regression analyses on sparse data, a set of Boltzmann sigmoid curves was used to represent thermal conductivity of bentonite materials, $\lambda$ (Baumgartner 2006; Villar 2002):

$$
\lambda=A_{1}+\frac{\left(A_{2}-A_{1}\right)}{1+e^{\left(\frac{V_{50-S_{r}}}{h}\right)}}
$$

where $A_{1}$ is the thermal conductivity of dry sample $(\mathrm{Sr}=0 \%), \mathrm{A}_{2}$ is the thermal conductivity of saturated sample $(\mathrm{Sr}=100 \%), \mathrm{V}_{50}$ and $\mathrm{h}$ are regression parameters, which are a function of dry density and listed in Table 5. Baumgartner (2006) also suggested an equation for specific heat capacity based on the composition of the material: 


$$
C=\frac{S_{r} \cdot\left(G_{s} \cdot \rho_{w}-\rho_{d}\right) \cdot C_{w}+G_{s} \cdot \rho_{d} \cdot \sum_{i=1}^{n}\left(f_{i} \cdot C_{i}\right)}{\left[G_{s} \cdot \rho_{d}+S_{r} \cdot\left(G_{s} \cdot \rho_{w}-\rho_{d}\right)\right]}
$$

where $C_{w}$ is specific heat capacity of water and $C_{i}$ is specific heat capacity of solid constituent material in which the value of $4186 \mathrm{~J} / \mathrm{kg} . \mathrm{K}$ and $800 \mathrm{~J} / \mathrm{kg} . \mathrm{K}$ was suggested for water and highly compacted bentonite or gapfill respectively (Baumgartner 2006) and $f_{i}$ is mass fraction of solid constituent material.

For all tests reported here, measured values are plotted versus predicted values using [6] and [7] in Figure 12. To evaluate the fit, statistics including mean $(\mu)$, standard deviation $(\sigma)$, and coefficient of variation $(\mathrm{COV})$ were determined for the bias of each measurement. Bias is calculated as:

$$
\text { bias }=\frac{\text { measured value }}{\text { predicted value }}
$$

and COV is:

$$
\operatorname{COV}=100 \% *\left(\frac{\sigma}{\mu}\right)
$$

where $\sigma=$ standard deviation of the bias and $\mu=$ mean of the bias. Using these definitions an ideal model has bias mean $=1.0$ and bias $\mathrm{COV}=0 \%$. The data on Figure 12 is plotted on a 1:1 scale to allow for visualization of the fit and the $+-1 \sigma$ shows the variation in the data. In general, Baumgartner empirical model under-predicts thermal conductivity of highly compacted bentonite (Figure 12a) with mean above 1.0 and COV of $7.6 \%$ and $8.1 \%$ for highly compacted bentonite made from MX80 and National Standard respectively. The fit is best at low values of thermal conductivity with some deviation noted at higher values. Specific heat capacity on Figure $12 \mathrm{c}$ shows COV equal to $8.4 \%$ and $5.0 \%$ for highly compacted bentonite made from MX80 and National Standard respectively. For gapfill thermal conductivity, the Baumgartner equations overestimate thermal conductivity (bias mean $=0.86$ 0.87). Gapfill, being a pelletized material which is then mixed with water, has a non-uniform moisture distribution at low saturations. This heterogeneity combined with the increased air content (due to the lower overall dry density) results in a lower thermal conductivity and less agreement with the proposed equations. With respect to specific heat capacity, again the predictions perform inadequately with 
$\mathrm{COV}=24 \%$ for National Standard and $17 \%$ for MX80. This trend again is attributed to the heterogeneity in the air and moisture distribution and the greater air content in comparison with highly compacted bentonite, thereby, due to the higher specific heat capacity of dry air and water (1000 J/kg.K and 4186 $\mathrm{J} / \mathrm{kg} . \mathrm{K}$ respectively) compared to specific heat capacity of solid constituent ( $800 \mathrm{~J} / \mathrm{kg} . \mathrm{K})$, higher values were measured.

\section{Statistical Comparison of Thermal Conductivity Measurements with Selected Models}

Selected thermal conductivity models for soil were compared with the thermal conductivity data for highly compacted bentonite, gapfill, and dense backfill. Similar to Figure 12, thermal conductivity measurements were compared to predicted values and bias statistics were generated (equations [5] and [6]). Thermal conductivity models by Cote and Konrad (2005), Balland and Arp (2005), Lu et al. (2007), Tang et al. (2008), and Sakashita and Kumada (1998) are used in the statistical comparison. Table 4 includes a summary of the equations used in the thermal conductivity models and the inputs. BarryMacaulay et al. (2015) and Tang et al. (2008) contain detailed information on the thermal conductivity models and brief descriptions are included here for brevity. Models by Cote and Konrad (2005), Balland and Arp (2005), and Lu et al. (2007) are based on Johansen (1975) and include the same equation for thermal conductivity (Equation [13] in Table 4). Johansen (1975) related thermal conductivity of frozen and unfrozen soils in terms of their saturated and dry thermal conductivities and the Kersten number, $\mathrm{K}_{\mathrm{e}}$, which is a function of saturation. Cote and Konrad (2005) developed their own equations for saturated and dry thermal conductivity (Equations [14] and [15]) based on the soils constituent materials, porosity, and empirical parameters to account for particle shape. They also accounted for a Kersten number equation (Equation [16]), which includes an empirical parameter for soil type and is a function of saturation. Balland and Arp (2005) developed a thermal conductivity model, based on Johansen (1975), that considers organic matter and includes new equations for solid particle conductivity, dry thermal conductivity, and Kersten number (Equations [17], [18], [19], [20]). Lu et al. (2007) improved the Johansen (1975) model at low degrees of saturation by introducing a new equation for Kersten number 
(Equation [22]) and an empirical linear relationship for dry thermal conductivity as a function of porosity (Equation [23]). Tang et al. (2008) examined thermal conductivity of bentonite and found that thermal conductivity has a linear relationship with the volume fraction of air $\left(\mathrm{V}_{\mathrm{a}} / \mathrm{V}\right)$ as listed in Equation [24]. They compared their model with Sakashita and Kumada (1998) who proposed empirical equations for thermal conductivity as a function of saturation and porosity.

A summary of the bias statistics appears in Table 5 for the Baumgartner (2006), Cote and Konrad (2005), Balland and Arp (2005), Lu et al. (2007), Tang et al. (2008), and Sakashita and Kumada (1998) thermal conductivity models. Although dense backfill only includes $5 \%$ of bentonite in its composition, thermal conductivity models developed for bentonite are included in the comparisons. Parameters listed in Table 5 for each thermal conductivity model include 'base' parameters as suggested in the original publications as well as 'fit' (or optimized) parameters, which were evaluated using Excel Solver function. In every case on Table 5, the optimized parameters provide a lower COV compared with the base parameters. Also highlighted on the table is the model that gave the lowest COV for each material using both base and optimized parameters. The only exceptions, which didn't incorporate optimized parameters are the Baumgartner (2006) model as its parameters $\left(A_{1}, A_{2}, V_{50}, h\right)$ are all linear or quadratic functions of dry density. This over-constrained the solution and a unique solution was not possible. The other exception is Tang et al. (2008) model, which already incorporates optimization in its empirical determination of thermal conductivity as a function of volume fraction of air (volume of air / total volume).

General comments can be made with respect to the agreement between the experimental data for the materials tested and each thermal conductivity model based on the statistics in Table 5. The Cote and Konrad model is consistent for these materials with COV ranging from $20-33 \%$ for base parameters. Highly compacted bentonite was under-predicted $(\mu=1.13-1.5)$ and gapfill was over-predicted $(\mu=0.91)$. For optimized parameters mean approached 1.0 and COV decreased for all materials to the $2.9-10.2 \%$. The Cote and Konrad model had the lowest COV for both highly compacted bentonite materials, which 
had a linear relationship between degree of saturation and thermal conductivity (Figure 7). Comparisons are plotted in Figure 13a and 13b. The Balland and Arp (2005) model had relatively higher COV for the bentonite-based materials (COV $>39 \%$ ) and lower for dense backfill with COV, which also significantly improved for the optimized parameters (COV between 4.3-9.5\%). Balland and Arp (2005) model fit best to the gapfill - MX80 data of all models and was a close second for the gapfill - National Standard. The Lu et al. (2007) model had consistent COV in the $26-38 \%$ range for base parameters which dropped to as low as $5.8 \%$ for optimized. This model fit best to the dense backfill. The Tang et al. (2008) model, incorporates fitting the data to generate input parameters and showed the best agreement to the highly compacted bentonites and dense backfill for base experimental data. Finally, the Sakashita and Kumada (1998) model had some of the lower COV values for all materials on the base columns, which were further improved upon for the optimized numbers. This model fit best to the gapfill - National Standard measurements.

Outcomes of the statistical analysis of the thermal conductivity models allows for some recommendations to be drawn. The number of thermal conductivity measurements performed for this study (206 total), allow for statistics to be evaluated on predictive models as well as soil-specific calibrations. The suggested parameters for these thermal conductivity models provide an estimation that may be useful for preliminary calculations. However, the number thermal conductivity measurements completed for this study allowed for soil-specific calibration, which improved the statistics for each case. Using these developed thermal property models future modelling efforts can examine the effect of variability in the material properties on dissipation of thermal energy in concepts for Canada's deep geologic repository.

\section{CONCLUSIONS}

Analysis of proposed concepts for a deep geologic repository requires reliable material properties. The deep geologic repository will encounter transient hydraulic, chemical, thermal, and 
mechanical conditions during its lifetime. A key aspect in the dissipation of thermal energy is the thermal properties of the sealing materials to meet the design criterion of maximum surface temperature of the used fuel container of $100^{\circ} \mathrm{C}$. Another decision that remains is whether MX80 or National Standard will be the bentonite used in the Canadian deep geological repository. The purpose of this study was to measure, report, compare, and comment on material properties of the highly compacted bentonite, gapfill, and dense backfill with consideration to bentonite source, porewater chemistry, temperature, variability, and moisture content. Increasing porewater chemistry serves to significantly reduce plasticity and swelling potential and increase optimum dry density, which agrees with anticipated trends from literature. The results show that although the bentonite properties affects index properties including plasticity, swelling potential, and has a nominal effect on compaction, its effect on the thermal properties was limited. Some more sensitivity was noted at high saturation and elevated temperature for gapfill due to its lower overall density and spatial variability of moisture within the pellet structure of gapfill. Variation of thermal conductivity with saturation was linear for highly compacted bentonite and dense backfill as the pore space filled up with water. Gapfill thermal conductivity showed nonlinear trends with very little increase in thermal conductivity at low saturation due to the water being isolated around the pellets rather than distributed uniformly as in the highly compacted bentonite. Increased temperature caused an increase in thermal properties with an attenuated effect on highly compacted bentonite owing to its high density. Dense backfill has the greatest thermal conductivity across the range of moisture contents due to its high quartz content within the crushed granite component. Thermal conductivity results are comparable with those from the literature with similar dry densities. Finally, the results were compared with selected thermal property models from the literature. Using the base parameters, thermal property models performed adequately, however, the soil-specific calibration of the model inputs improved the fit significantly in all cases. These results are now available to perform the numerical models to examine the impact of variability in material properties for the proposed Canadian deep geologic repository for used nuclear fuel. 


\section{ACKNOWLEDGEMENTS}

The authors are grateful for the support provided by Nuclear Waste Management Organization (NWMO), Natural Sciences and Engineering Research Council, Queen`s University, Royal Military College of Canada, Department of National Defence, Canadian Geotechnical Society, and Ontario Graduate Scholarship Program.
ABBREVIATIONS
${ }^{\circ} \mathrm{C}$
a
$\mathrm{a}, \alpha, \beta$
$\mathrm{a}, \mathrm{b}, \alpha$
$a, b, c, d, e, f, g$
ANDRA
ASTM
C
COV
$\mathrm{D}\left(\tau_{\mathrm{c}}\right)$
DOE
ENRESA
$\mathrm{G}_{\mathrm{s}}$
HCB
JNC
K
$\mathrm{K}_{\text {sat }}$, a
M
MX80
n
degrees Celcius
radius of the sensors largest ring
fitting parameters for Balland and Arp (2005) thermal conductivity model
fitting parameters for Lu et al. (2007) thermal conductivity model
fitting parameters for Sakashita and Kumada (1998) thermal conductivity model
National Radioactive Waste Management Agency (France)
American Society for Testing and Materials
Specific Heat Capacity
Coefficient of Variation
dimensionless time dependent function
Department of Energy (Unites States of America)
National Radioactive Waste Management Agency (Spain)
Specific Gravity
Highly Compacted Bentonite
Nuclear Cycle Development Institute (Japan)
thermal conductivity
fitting parameters for Tang et al. (2008) thermal conductivity model
Mass
MX80 Bentonite
number of thermal conductivity measurements 


\begin{tabular}{|c|c|}
\hline NAGRA & Radioactive Waste Disposal Agency (Switzerland) \\
\hline NWMO & Nuclear Waste Management Organization (Canada) \\
\hline ONDRAF/NIRAS & National radioactive waste and enriched fissile materials organization (Belgium) \\
\hline $\mathrm{P}_{\mathrm{o}}$ & power output of the sensor \\
\hline $\mathrm{R}_{\mathrm{o}}$ & resistance of disk prior to heating \\
\hline $\mathrm{t}$ & time \\
\hline $\mathrm{T}$ & temperature \\
\hline TDS & Total Dissolved Solid \\
\hline $\mathrm{Sr}$ & Degree of Saturation \\
\hline $\mathrm{x}, \mathrm{y}, \mathrm{z}$ & cartesian coordinates \\
\hline $\mathrm{w}$ & Bulk Water Content \\
\hline $\mathrm{w}_{1}$ & Solution Water Content \\
\hline$\alpha$ & temperature coefficient of resistivity of nickel \\
\hline$\delta$ & thickness of the insulating material \\
\hline$\Delta \mathrm{T}_{\mathrm{i}}$ & constant temperature difference that develops across the sensor insulation \\
\hline$\Delta \mathrm{T}_{\mathrm{avg}}(\tau)$ & average temperature increase of the specimen surface in contact with the sensor \\
\hline$\lambda$ & thermal conductivity \\
\hline$\kappa$ & thermal diffusivity \\
\hline$\kappa_{\mathrm{j}}$ & thermal diffusivity of the insulating material \\
\hline$\kappa, \chi, \eta$ & fitting parameters for Cote and Konrad (2005) thermal conductivity model \\
\hline$\mu$ & mean \\
\hline$\rho_{\mathrm{d}}$ & Dry Density \\
\hline$\rho_{\text {sol }}$ & Solution Density \\
\hline$\rho_{\mathrm{w}}$ & Water Density \\
\hline$\sigma$ & standard deviation \\
\hline$\theta$ & characteristic time \\
\hline
\end{tabular}




\section{REFERENCES}

ASTM International. 2010. ASTM D4318-10e1 Standard Test Methods for Liquid Limit, Plastic Limit, and Plasticity Index of Soils, http://dx.doi.org/10.1520/D4318.

ASTM International. 2011. ASTM D5890-11 Standard Test Method for Swell Index of Clay Mineral Component of Geosynthetic Clay Liners, http://dx.doi.org/10.1520/D5890-11.

ASTM International. 2012. ASTM D1557-12e1 Standard Test Methods for Laboratory Compaction Characteristics of Soil Using Modified Effort $\left(56,000 \quad \mathrm{ft}-\mathrm{lbf} / \mathrm{ft}^{3} \quad\left(2,700 \mathrm{kN}-\mathrm{m} / \mathrm{m}^{3}\right)\right)$. http://dx.doi.org/10.1520/D1557-12E01.

Ali, M.A., Bouazza, A., Singh, R.M., Gates, W.P., and Rowe, R.K. 2016. Thermal conductivity of geosynthetic clay liners. Canadian Geotechnical Journal. 53: 1510-1521.

Balland, V., and Arp, P. A. 2005. Modeling soil thermal conductivities over a wide range of conditions. Journal of Environmental Engineering and Science, 4(6), pp. 549-558.

Barry-Macaulay, D., Bouazza, A., Wang, B., and Singh, R. M. 2015. Evaluation of soil thermal conductivity models. Canadian Geotechnical Journal, 52(11), pp. 1892-1900.

Baumgartner, P. 2000. Elemental composition of disposal vault sealing materials. Atomic Energy of Canada Ltd, AECL, TR-06818.

Baumgartner, P. 2006. Generic thermal-mechanical-hydraulic (THM) data for sealing materials-Volume 1: Soil-water relationships. Atomic Energy of Canada Ltd, AECL, TR-06819.

Benfield, A.E. 1939. Terrestrial heat in Great Britain. Proc. R. Soc. Lond. A: Math. Phys. Sci. 173, 428450.

Bullard, E.C. 1939. Heat flow in South Africa. Proc. R. Soc. Lond. A: Math. Phys. Sci. 173, 474-502.

Beziat, A., Dardaine, M., and Gabis, V. 1988. Effect of compaction pressure and water content on the thermal conductivity of some natural clays. Clays and Clay Minerals, 36(5), pp. 462-466.

Börgesson, L., Fredrikson, A., and Johannesson, L. E. 1994. Heat conductivity of buffer materials. Swedish Nuclear Fuel and Waste Management Co, SKB, 94-29. 
Côté, J., and Konrad, J. M. 2005. Thermal conductivity of base-course materials. Canadian Geotechnical Journal, 42(1), pp. 61-78

Coulon, H., Lajudie, A., Debrabant, P., Atabek, R., Jorda, M., and Andre-Jehan R. 1987. Choice of french clays as engineered barrier components for waste disposal. In MRS Proceeding, Cambridge University Press, 84, p. 813.

De Vries, D.A., and Peck, A.J. 1958. Onthe cylindrical probe method of measuring thermal conductivity with special reference to soils. Aust. J. Phys. 11, 255-271.

Dixon, D. A., Gray, M. N., and Thomas, A. W. 1985. A study of the compaction properties of potential clay-sand buffer mixtures for use in nuclear fuel waste disposal. Engineering Geology, 21(3-4): pp. 247-255.

Dong, Y., Lu, N., Wayllace, A., and Smits, K. 2014. Measurement of Thermal Conductivity Function of Unsaturated Soil Using a Transient Water Release and Imbibition Method. ASTM Geotechnical Testing Journal. 37(6): 980-990.

Engelhardt, I., and Finsterle, S. 2003. Thermal-hydraulic experiments with bentonite/crushed rock mixtures and estimation of effective parameters by inverse modeling. Applied Clay Science, 23(1): 111-120.

Engineering Tool Box 2017. http://www.engineeringtoolbox.com. Accessed September 2017.

Farouki, O. T. 1986. Thermal properties of soils. Trans Tech Publications, vol. 11.

Garamszeghy, M. 2015. Nuclear Fuel Waste Projections in Canada-Update. Nuclear Waste Management Organization, NWMO, TR-2015-19.

Graham, J., Chandler, N.A., Dixon, D.A., Roach, P.J., To, T., and Wan, A.W.L. 1997. The Buffer/Container Experiment: Results. Atomic Energy of Canada Ltd, TR-11746.

Golder Associates Ltd, 2013. Bentonite seal properties in saline water. SA440-2013 (unpublished report)

He, Y. 2005. Rapid thermal conductivity measurement with a hot disk sensor: Part 1. Theoretical considerations. Thermochimica Acta, 436(1), pp. 122-129. 
Hot Disk. 2014. Hot Disk Thermal Constants Analyser - Instruction Manual.

Johansen, O. 1975. Thermal conductivity of soils. Ph.D. thesis, University of Trondheim CRREL Draft English Translation 637, 1977.Kim, C.S., Man, A., Dixon, D. Holt., E., and Fritzell, A. 2012. Clay-based pellets for use in tunnel backfill and as gap fill in a deep geological repository: characterisation of thermal-mechanical Properties. Nuclear Waste Management Organization, NWMO, TR- 2012-05.

Kahr, G., and Müller-Vonmoos, M. 1982. Wärmeleitfähigkeit von Bentonite MX80 und von Montigel nach der Heizdrahtmethode. NTB 82-06. Nagra, Hardstrasse 73, CH-5430 Wettingen, Schweiz.

Kodikara, J., Rajeev, P., and Rhoden, N.J. 2011. Determination of thermal diffusivity of soil using infrared thermal imaging. Canadian Geotechnical Journal. 48: 1295-1302.

Lee, J. M., and Shackelford, C. D. 2005. Solution retention capacity as an alternative to the swell index test for sodium bentonite. Geotechnical Testing Journal, 28(1), pp. 61-70.

Lee, J.O., Choi, H., and Lee, J.Y. 2016. Thermal conductivity of compacted bentonite as a buffer material for a high-level radioactive waste repository. Annals of Nuclear Energy. 94: 848-855.

Likos, W. J. 2015. Pore-scale model for thermal conductivity of unsaturated sand. Geotechnical and Geological Engineering Journal, 33(2), pp. 179-192.

Lu, S., Ren, T., Gong, Y., and Horton, R. 2007. An improved model for predicting soil thermal conductivity from water content at room temperature. Soil Science Society of America Journal, 71(1), pp. 8-14.

Maak, P. 2006. Used fuel container requirements. Ontario Power Generation Preliminary Design Requirements.

Madsen, F. T. 1998. Clay mineralogical investigations related to nuclear waste disposal. Clay Minerals, 33(1), pp. 109-129.

Man, A., Martino, J.S., Kim, C.S., and Priyanto, D.G. 2011. Characterization and improving the thermal conductivity of engineered clay barriers for sealing a deep geological repository. Waste 
Management, Decommissioning and Environmental Restoration for Canada's Nuclear Activities, Toronto, Canada.

Mitchell, J.K. 1976. Fundamentals of soil behaviour. John Wiley \& Sons, Toronto, Ont.

McGuiness, T., Hemmingway, P., and Long, M. 2014. Design and Development of a Low-Cost Divided-Bar Apparatus. ASTM Geotechnical Testing Journal. 37(2): 230-241.

NWMO 2015. Ensuring safety: multiple-barrier System (background)

Ould-Lahoucine, C., Sakashita, H., and Kumada, T. 2002. Measurement of thermal conductivity of buffer materials and evaluation of existing correlations predicting it. Nuclear Engineering and Design Journal, 216(1), pp. 1-11.

Pasquale, V., Verdoya, M., and Chiozzi, P. 2015. Measurements of rock thermal conductivity with a Transient Divided Bar. Geothermics. 53: 183-189.

Priyanto, D.G., Kim, C.S. and Dixon, D.A. 2013. Geotechnical characterization of a potential shaft backfill material. Nuclear Waste Management Organization, NWMO, TR- 2013-03.

Pusch, R. 1979. Highly compacted sodium bentonite for isolating rock-deposited radioactive waste products. Nuclear Technology, 45(2), pp. 153-157.

Radhakrishna, H. S., Chan, H. T., Crawford, A. M., and Lau, K. C. 1989. Thermal and physical properties of candidate buffer-backfill materials for a nuclear fuel waste disposal vault. Canadian Geotechnical Journal, 26(4), pp. 629-639.

Sakashita, H., and Kumada, T. 1998. Heat transfer model for predicting thermal conductivity of highly compacted bentonite. Nippon Genshiryoku Gakkai-Shi, 40(3), pp. 235-240

Schmitt, M., Poffo, C.M., de Lima, J.C., Fernandes, C.P., and dos Santos, V.S.S. 2017. Application of photoacoustic spectroscopy to characterize thermal diffusivity and porosity of caprocks. Engineering Geology. 220: 183-195.

Salo, J. P., and Kukkola, T. 1989. Bentonite pellets, an alternative buffer material for spent fuel canister deposition holes. Sealing of Radioactive Waste Repositories. 
Suzuki, H., Shibata, M., Yamagata, J., Hirose, I. and Terakado, K., 1992. Physical and mechanical properties of bentonite (I), PNC TN1410 92-52 (in Japanese).

Tang, A.M. and Cui, Y.J. 2010. Effects of mineralogy on thermo-hydro-mechanical parameters of MX 80 bentonite. Journal of Rock Mechanics and Geotechnical Engineering. 2(1): 91-96.

Tang, A. M., Cui, Y. J., and Le, T. T. 2008. A study on the thermal conductivity of compacted bentonites. Applied Clay Science, 41(3), pp. 181-189.

Villar Galicia, M. V. 2002. Thermo-hydro-mechanical characterisation of a bentonite from Cabo de Gata: A study applied to the use of bentonite as sealing material in high level radioactive waste repositories. Ph.D. thesis, Departamento de Geodinámica, Facultad de Ciencias Geológicas, Universidad Complutense de Madrid.

Volckaert, G., Bernier, F., Alonso, E., Gens, A., Samper, J., Villar, M., Martin-Martin, P.L., Cuevas, J., Campos, R., Thomas, H., and Imbert, C. 1996. Thermal-hydraulic-mechanical and geochemical behaviour of the clay barrier in radioactive waste repositories (model development and validation). Publication of European Communities, EUR, 16744, p.772.

Von Herzen, R.P., and Maxwell, A.E. 1959. The measurement of thermal conductivity of deep-sea sediments by a needle probe method. J. Geophys. Res. 64, 1557-1563.

Woodward, N.R., Tinjum, J.M., and Wu, R. 2013. Water Migration Impacts on Thermal Resistivity Testing Procedures. ASTM Geotechnical Testing Journal. 36(6): 948-955.

Yao, J., Oh, H., Likos, W.J., and Tinjum, J.M. 2014. Three Laboratory Methods for Measuring Thermal Resistivity Dryout Curves of Coarse-Grained Soils. ASTM Geotechnical Testing Journal. 37(6): 1056-1067.

Ye, W., Chen, Y., Chen, B., Wang, Q., and Wang, J. 2010. Advances on the knowledge of the buffer/backfill properties of heavily-compacted GMZ bentonite. Engineering Geology. 116: 2120. 


\section{LIST OF CAPTIONS}

Figure 1. Canadian concept of a deep geological repository and Mark II placement room (after NWMO 2015).

Figure 2. Typical grain-size distributions for a) gapfill and b) dense backfill granite and B-clay.

Figure 3. a) swell index and solution retention capacity results for all materials and b) correlation between solution retention capacity and swell index for saline porewater samples.

Figure 4. Compaction pressure versus degree of saturation and water content for preparation of thermal conductivity samples of highly compacted bentonite and dense backfill.

Figure 5. a) Thermal property sensor for $25^{\circ} \mathrm{C}$ tests, b) two-sided thermal test setup, c) one-sided test setup, d) typical $25^{\circ} \mathrm{C}$ test result plotted as temperature increase versus time, and e) typical temperature drift during thermal equilibrium phase of $80^{\circ} \mathrm{C}$ test.

Figure 6. Compaction results displaying influence of porewater salinity for: a) MX80 bentonite b) National Standard bentonite, and c) dense backfill.

Figure 7. Thermal properties of highly compacted bentonite displaying the effects of bentonite type, degree of saturation, and temperature.

Figure 8. Thermal properties of gapfill displaying the effects of bentonite type, degree of saturation, and temperature.

Figure 9. Thermal properties of dense backfill displaying the effects of degree of saturation and temperature.

Figure 10. Summary plot of thermal properties for highly compacted bentonite, gapfill, and dense backfill displaying effect of bentonite type, temperature, and degree of saturation on thermal conductivity and volumetric heat capacity.

Figure 11. Comparison of thermal conductivity data with previous studies plotted versus degree of saturation. Previous studies are FEBEX (Villar 2002), GMZ (Ye et al. 2010), Kunigel (Suzuki et al. 1992), Kyeongju (Lee et al. 2016), and MX80 (Tang et al. 2008).

Figure 12. Comparison between Baumgartner (2006) predictions and measured thermal properties of highly compacted bentonite and gapfill at $25^{\circ} \mathrm{C}$.

Figure 13. Comparison between measured and predicted values for thermal conductivity models with lowest COV (parameters in Table 5). 
Table 1. Material summary.

\begin{tabular}{lcc}
\hline Material & Composition & $\begin{array}{c}\text { Dry density } \\
\left(\mathbf{g} / \mathbf{c m}^{\mathbf{3}} \mathbf{)}\right.\end{array}$ \\
\hline highly compacted bentonite (HCB) & $100 \%$ bentonite & 1.7 \\
gapfill & $100 \%$ bentonite pellets (Figure 3a) & 1.4 \\
dense backfill & $70 \%$ crushed granite (Figure 3b) & 2.12 \\
& $25 \%$ B-clay (Figure 3b) \\
& $5 \%$ bentonite \\
\hline
\end{tabular}

Table 2. Material constituent properties.

\begin{tabular}{lcccc}
\hline Material & $\begin{array}{c}\text { Montmorillonite } \\
\text { content } \\
(\%)\end{array}$ & $\begin{array}{c}\text { Quartz } \\
\text { content } \\
(\%)\end{array}$ & $\begin{array}{c}\text { Liquid } \\
\text { limit } \\
(\%)\end{array}$ & $\begin{array}{c}\text { Plasticity } \\
\text { index }\end{array}$ \\
\hline MX80 bentonite & 84.6 & 8.6 & 322 & 287 \\
National Standard bentonite & 87.3 & 6.6 & 611 & 564 \\
B-Clay & 0 & 49.5 & 32 & 18 \\
Lac du Bonnet Granite & 0 & 36.9 & - & - \\
dense backfill & $<5$ & 33.5 & 39 & 25 \\
\hline
\end{tabular}

${ }^{\mathrm{I}}$ ASTM D4318

${ }^{2}$ values in brackets are with SR-L-2013 used as the porewater.

Table 3. SR-L-2013 porewater composition.

\begin{tabular}{cc} 
Ion & $\begin{array}{c}\text { Concentration } \\
(\mathbf{g} / \mathbf{L})\end{array}$ \\
\hline $\mathrm{Na}$ & 46 \\
$\mathrm{Ca}$ & 19.4 \\
$\mathrm{~K}$ & 17.6 \\
$\mathrm{Mg}$ & 4.86 \\
$\mathrm{Cl}$ & 135.1 \\
$\mathrm{SO}_{4}$ & 0.48 \\
Total & $\mathbf{2 2 3 . 4}$ \\
\hline
\end{tabular}


Table 4. Thermal conductivity model equations and inputs.

Thermal

Conductivity

Model

\begin{tabular}{lll}
\hline Cote and Konrad & $\lambda=\left(\lambda_{\text {sat }}-\lambda_{\text {dry }}\right) \mathrm{K}_{\mathrm{e}}+\lambda_{\text {sat }}$ & \\
$\mathbf{( 2 0 0 5 )}$ & $\lambda_{\text {sat }}=\lambda_{\mathrm{s}}^{\theta_{\mathrm{s}}} \lambda_{\mathrm{w}}^{\theta_{\mathrm{w}}} \lambda_{\mathrm{i}}^{\theta_{\mathrm{i}}}$ & \\
& $\lambda_{\text {dry }}=\chi\left(10^{-\eta n \mathrm{n}}\right)$ & \\
& $\mathrm{K}_{\mathrm{e}}=\frac{\kappa \mathrm{S}_{\mathrm{r}}}{1+(\kappa-1) \mathrm{S}_{\mathrm{r}}}$ &
\end{tabular}

\section{Equations}

[13]

-

Inputs

\begin{tabular}{cccccc} 
& $\begin{array}{c}\text { HCB } \\
\text { MX80 }\end{array}$ & $\begin{array}{c}\text { HCB Nat } \\
\text { Std }\end{array}$ & $\begin{array}{c}\text { gapfill } \\
\text { MX80 }\end{array}$ & $\begin{array}{c}\text { gapfill } \\
\text { Nat Std }\end{array}$ & $\begin{array}{c}\text { dense } \\
\text { backfill }\end{array}$ \\
\hline$\kappa$ & 1.90 & 1.90 & 1.90 & 1.90 & 4.60 \\
$\chi$ & 0.75 & 0.75 & 0.75 & 0.75 & 1.70 \\
\hline
\end{tabular}

$\begin{array}{cccccc}\chi & 0.75 & 0.75 & 0.75 & 0.75 & 4.60 \\ \eta & 1.20 & 1.20 & 1.20 & 1.20 & 1.80 \\ \lambda_{\text {sat }} & 1.33 & 1.34 & 1.14 & 1.15 & 2.24\end{array}$

$\begin{array}{cccccc}\lambda_{\text {sat }} & 1.33 & 1.34 & 1.14 & 1.15 & 2.24 \\ \lambda_{\text {dry }} & 0.26 & 0.27 & 0.19 & 0.20 & 0.44 \\ \lambda_{\text {s }} & 2.25 & 2.19 & 2.25 & 2.19 & 3.14\end{array}$

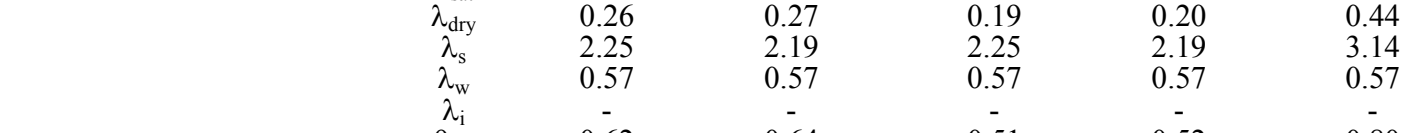

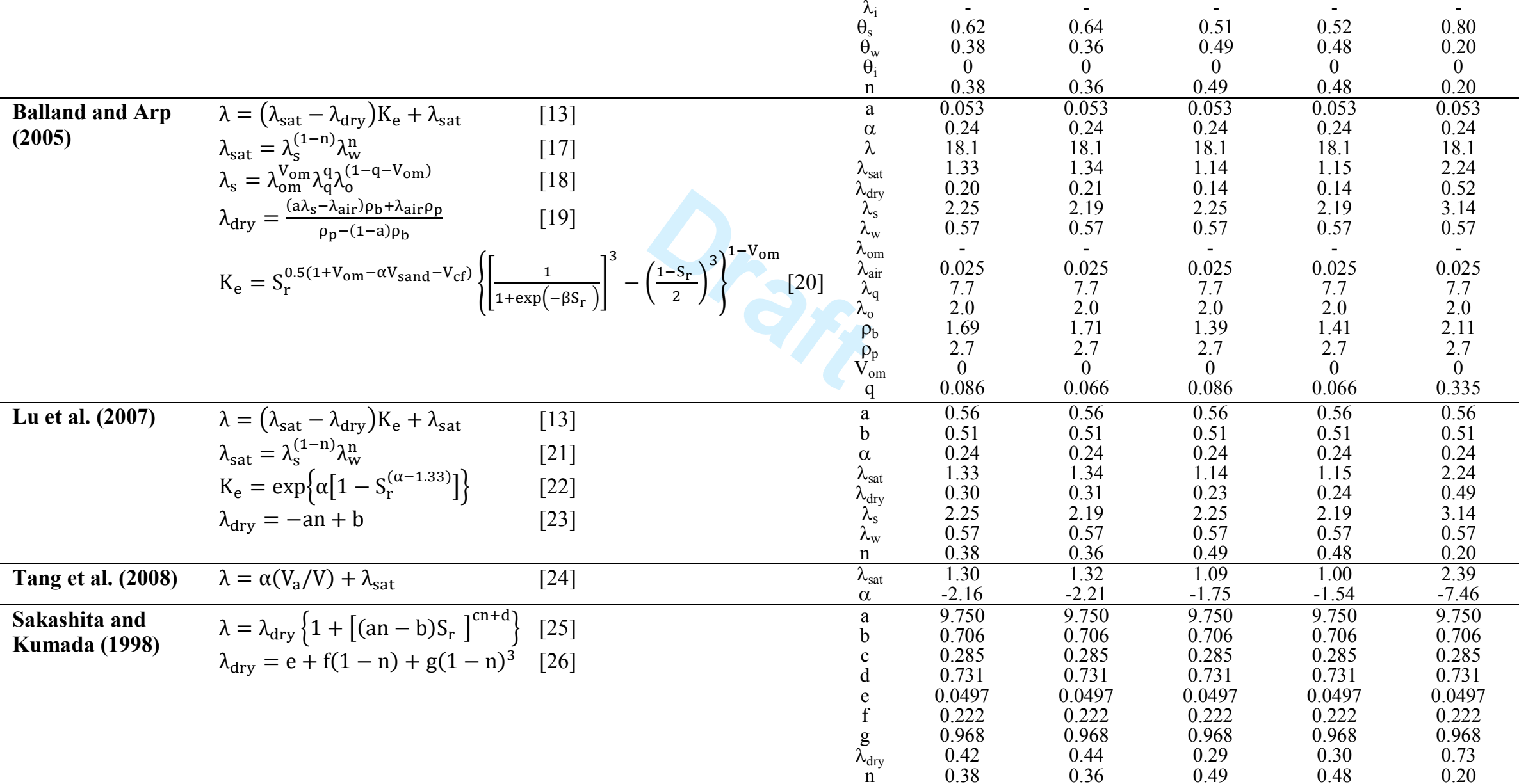

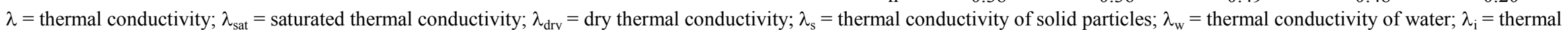

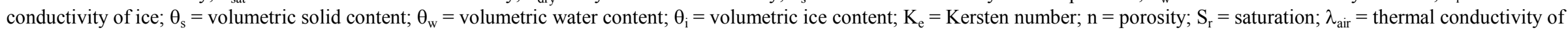
air; $\lambda_{\mathrm{q}}=$ thermal conductivity of quartz; $\lambda_{\mathrm{o}}=$ thermal conductivity of organic material; $\rho_{\mathrm{b}}=$ dry density; $\rho_{\mathrm{p}}=$ solid particle density; $\mathrm{V}_{\mathrm{om}}=$ volumetric organic matter content; $\mathrm{q}=$ quartz content; $\mathrm{V}_{\mathrm{a}}=$ volumetric air content; $\mathrm{V}=$ total volume; 
Table 5. Statistical evaluation of selected thermal conductivity models.

\begin{tabular}{|c|c|c|c|c|c|c|c|c|c|c|c|}
\hline \multirow[t]{2}{*}{ Thermal Conductivity Model } & \multirow[t]{2}{*}{$\begin{array}{c}\text { Parameters } \\
\text { and } \\
\text { statistics }\end{array}$} & \multicolumn{2}{|c|}{$\begin{array}{c}\text { highly compacted } \\
\text { bentonite } \\
- \text { MX80 } \\
\mathbf{n}=42\end{array}$} & \multicolumn{2}{|c|}{$\begin{array}{c}\text { highly compacted } \\
\text { bentonite } \\
\text { - National Standard } \\
\mathbf{n}=\mathbf{3 6}\end{array}$} & \multicolumn{2}{|c|}{$\begin{array}{c}\text { gapfill } \\
- \text { MX80 } \\
\mathbf{n}=\mathbf{3 3}\end{array}$} & \multicolumn{2}{|c|}{$\begin{array}{c}\text { gapfill } \\
\text { - National Standard } \\
\mathbf{n}=\mathbf{4 0} \\
\end{array}$} & \multicolumn{2}{|c|}{$\begin{array}{c}\text { dense } \\
\text { backfill } \\
n=45\end{array}$} \\
\hline & & Base & Fit & Base & Fit & Base & Fit & Base & Fit & Base & Fit \\
\hline Baumgartner (2006) & $\begin{array}{c}\mu \\
\mathrm{COV}\end{array}$ & $\begin{array}{l}1.10 \\
7.6 \% \\
\end{array}$ & -1 & $\begin{array}{c}1.14 \\
8.1 \% \\
\end{array}$ & - & $\begin{array}{c}0.87 \\
5.8 \% \\
\end{array}$ & - & $\begin{array}{c}0.86 \\
10 \%^{2} \\
\end{array}$ & - & - & - \\
\hline \multirow[t]{2}{*}{ Cote and Konrad (2005) } & $\begin{array}{l}\kappa \\
\chi \\
\eta\end{array}$ & $\begin{array}{l}1.90 \\
0.75 \\
1.20\end{array}$ & $\begin{array}{l}0.72 \\
3.10 \\
2.10\end{array}$ & $\begin{array}{l}1.90 \\
0.75 \\
1.20\end{array}$ & $\begin{array}{l}0.95 \\
2.65 \\
1.92\end{array}$ & $\begin{array}{l}1.90 \\
0.75 \\
1.20\end{array}$ & $\begin{array}{l}0.67 \\
42.8 \\
4.50\end{array}$ & $\begin{array}{l}1.90 \\
0.75 \\
1.20\end{array}$ & $\begin{array}{l}0.46 \\
1.19 \\
1.18\end{array}$ & $\begin{array}{l}4.60 \\
1.70 \\
1.80\end{array}$ & $\begin{array}{c}1.25 \\
0.83 \\
0\end{array}$ \\
\hline & $\stackrel{\mu}{\mathrm{COV}}$ & $\begin{array}{c}1.13 \\
26.6 \%\end{array}$ & $\frac{1.02}{4.0 \% \%^{3}}$ & $\begin{array}{c}1.15 \\
24.0 \%\end{array}$ & $\underline{0.99}^{2.9 \%}{ }^{3}$ & $\begin{array}{c}0.91 \\
25.0 \% \\
\end{array}$ & $\begin{array}{c}1.03 \\
5.0 \%\end{array}$ & $\begin{array}{c}0.91 \\
33.3 \%\end{array}$ & $\begin{array}{c}0.97 \\
8.0 \%\end{array}$ & $\begin{array}{c}0.89 \\
19.8 \% \\
\end{array}$ & $\begin{array}{c}1.04 \\
10.2 \% \\
\end{array}$ \\
\hline \multirow[t]{2}{*}{ Balland and Arp (2005) } & $\begin{array}{l}\mathrm{a} \\
\alpha \\
\beta\end{array}$ & $\begin{array}{c}0.053 \\
0.24 \\
18.1\end{array}$ & $\begin{array}{c}0.169 \\
0.24 \\
4.27\end{array}$ & $\begin{array}{c}0.053 \\
0.24 \\
18.1\end{array}$ & $\begin{array}{c}0.196 \\
0.24 \\
4.48\end{array}$ & $\begin{array}{c}0.053 \\
0.24 \\
18.1\end{array}$ & $\begin{array}{l}0.112 \\
0.24 \\
2.66\end{array}$ & $\begin{array}{c}0.053 \\
0.24 \\
18.1\end{array}$ & $\begin{array}{c}0.117 \\
0.24 \\
2.02\end{array}$ & $\begin{array}{c}0.053 \\
0.24 \\
18.1\end{array}$ & $\begin{array}{c}0.113 \\
0.24 \\
6.71\end{array}$ \\
\hline & $\stackrel{\mu}{\mathrm{COV}}$ & $\begin{array}{c}1.23 \\
40.8 \% \\
\end{array}$ & $\begin{array}{l}1.00 \\
6.2 \% \\
\end{array}$ & $\begin{array}{c}1.24 \\
39.4 \% \\
\end{array}$ & $\begin{array}{l}0.96 \\
4.4 \%\end{array}$ & $\begin{array}{c}1.00 \\
40.9 \%\end{array}$ & $\frac{1.15}{4.3 \%}{ }^{3}$ & $\begin{array}{c}1.00 \\
51.9 \%\end{array}$ & $\begin{array}{c}1.17 \\
7.8 \%\end{array}$ & $\begin{array}{c}1.11 \\
25.8 \%\end{array}$ & $\begin{array}{l}1.00 \\
9.5 \%\end{array}$ \\
\hline \multirow[t]{2}{*}{ Lu et al. (2007) } & $\begin{array}{l}\mathrm{a} \\
\mathrm{b} \\
\alpha\end{array}$ & $\begin{array}{l}0.56 \\
0.51 \\
0.24\end{array}$ & $\begin{array}{r}2.50 \\
1.54 \\
0.585\end{array}$ & $\begin{array}{c}0.56 \\
0.51 \\
0.24\end{array}$ & $\begin{array}{r}3.22 \\
1.77 \\
0.575\end{array}$ & $\begin{array}{l}0.56 \\
0.51 \\
0.24\end{array}$ & $\begin{array}{r}2.73 \\
1.69 \\
0.535\end{array}$ & $\begin{array}{c}0.56 \\
0.51 \\
0.24\end{array}$ & $\begin{array}{r}2.76 \\
1.75 \\
0.511\end{array}$ & $\begin{array}{c}0.56 \\
0.51 \\
0.24\end{array}$ & $\begin{array}{c}0 \\
0.930 \\
0.441\end{array}$ \\
\hline & $\stackrel{\mu}{\mathrm{COV}}$ & $\begin{array}{c}1.13 \\
32.7 \% \\
\end{array}$ & $\begin{array}{c}0.85 \\
9.0 \% \\
\end{array}$ & $\begin{array}{c}1.15 \\
30.2 \% \\
\end{array}$ & $\begin{array}{c}0.87 \\
5.8 \% \\
\end{array}$ & $\begin{array}{c}0.89 \\
26.1 \% \\
\end{array}$ & $\begin{array}{c}0.79 \\
12.5 \% \\
\end{array}$ & $\begin{array}{c}0.88 \\
33.1 \% \\
\end{array}$ & $\begin{array}{c}0.71 \\
15.3 \% \\
\end{array}$ & $\begin{array}{c}1.26 \\
38.1 \% \\
\end{array}$ & $\begin{array}{r}\underline{0.96} \\
\underline{8.4 \%^{3}}\end{array}$ \\
\hline \multirow[t]{2}{*}{ Tang et al. (2008) } & $\begin{array}{c}\lambda_{\text {sat }} \\
\text { a }\end{array}$ & $\begin{array}{r}1.30 \\
-2.16\end{array}$ & -4 & $\begin{array}{r}1.32 \\
-2.22\end{array}$ & - & $\begin{array}{r}1.09 \\
-1.75\end{array}$ & - & $\begin{array}{r}1.00 \\
-1.55\end{array}$ & - & $\begin{array}{r}2.39 \\
-7.46\end{array}$ & - \\
\hline & $\stackrel{\mu}{\mathrm{COV}}$ & $\begin{array}{c}1.00 \\
5.1 \%^{2}\end{array}$ & - & $\begin{array}{c}1.00 \\
2.8 \%\end{array}$ & - & $\begin{array}{l}1.01 \\
9.1 \%\end{array}$ & - & $\begin{array}{l}1.01 \\
14 \% \\
\end{array}$ & - & $\begin{array}{c}1.00 \\
12.0 \%^{2}\end{array}$ & - \\
\hline \multirow[t]{7}{*}{ Sakashita and Kumada (1998) } & $\begin{array}{l}a^{5} \\
b\end{array}$ & $\begin{array}{c}0.0497 \\
0.222\end{array}$ & $\begin{array}{l}0 \\
0\end{array}$ & $\begin{array}{c}0.0497 \\
0.222\end{array}$ & $\begin{array}{l}0 \\
0\end{array}$ & $\begin{array}{c}0.0497 \\
0.222\end{array}$ & $\begin{array}{l}0 \\
0\end{array}$ & $\begin{array}{c}0.0497 \\
0.222\end{array}$ & $\begin{array}{l}0 \\
0\end{array}$ & $\begin{array}{c}0.0497 \\
0.222\end{array}$ & $\begin{array}{l}0 \\
0\end{array}$ \\
\hline & $\mathrm{c}$ & 0.968 & 2.00 & 0.968 & 2.01 & 0.968 & 2.19 & 0.968 & 2.31 & 0.968 & 2.21 \\
\hline & $\mathrm{d}$ & 9.75 & 3.89 & 9.75 & 4.24 & 9.75 & 4.71 & 9.75 & 3.61 & 9.75 & 8.39 \\
\hline & $\mathrm{e}$ & 0.706 & 0 & 0.706 & 0 & 0.706 & 0 & 0.706 & 0 & 0.706 & 0 \\
\hline & $\mathrm{f}$ & 0.285 & 0 & 0.285 & 0 & 0.285 & 0 & 0.285 & 0 & 0.285 & 0 \\
\hline & $\mathrm{g}$ & 0.731 & 1.19 & 0.731 & 1.06 & 0.731 & 1.31 & 0.731 & 1.59 & 0.731 & 1.04 \\
\hline & $\stackrel{\mu}{\mathrm{COV}}$ & $\begin{array}{c}0.94 \\
11.2 \%\end{array}$ & $\begin{array}{l}1.07 \\
4.5 \%\end{array}$ & $\begin{array}{c}0.95 \\
9.3 \%\end{array}$ & $\begin{array}{l}1.00 \\
3.3 \%\end{array}$ & $\begin{array}{c}0.80 \\
11.6 \%\end{array}$ & $\begin{array}{c}1.00 \\
4.8 \%\end{array}$ & $\begin{array}{c}0.77 \\
18.4 \%\end{array}$ & $\frac{1.00}{7.2 \%^{3}}$ & $\begin{array}{c}1.33 \\
12.8 \%\end{array}$ & $\begin{array}{c}0.80 \\
10.9 \%\end{array}$ \\
\hline
\end{tabular}

\footnotetext{
optimization not performed due to number of parameters
}

${ }^{2}$ lowest COV for 'Base' parameters appear in bold

${ }^{3}$ lowest COV for 'Fit' parameters are underlined and comparison plotted in Figure 12

${ }_{5}^{4}$ optimization not performed as model generates optimized parameters

${ }^{5}$ constants in Sakashita and Kumada equations for $\mathrm{K}_{\mathrm{dry}}$ and $\mathrm{K}$ have been assigned letter variables in this pape 


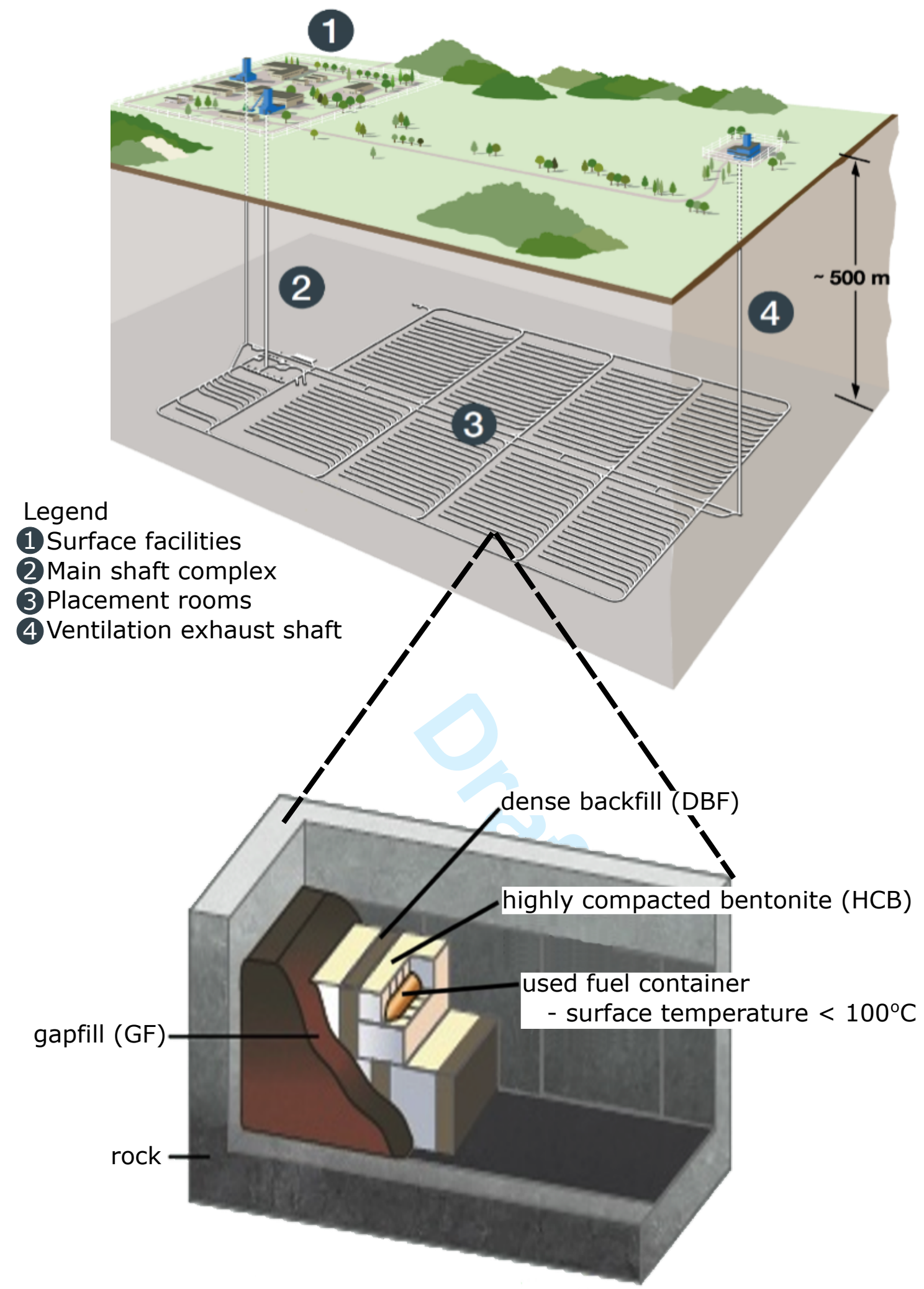




\section{Canadian Geotechnical Journal}
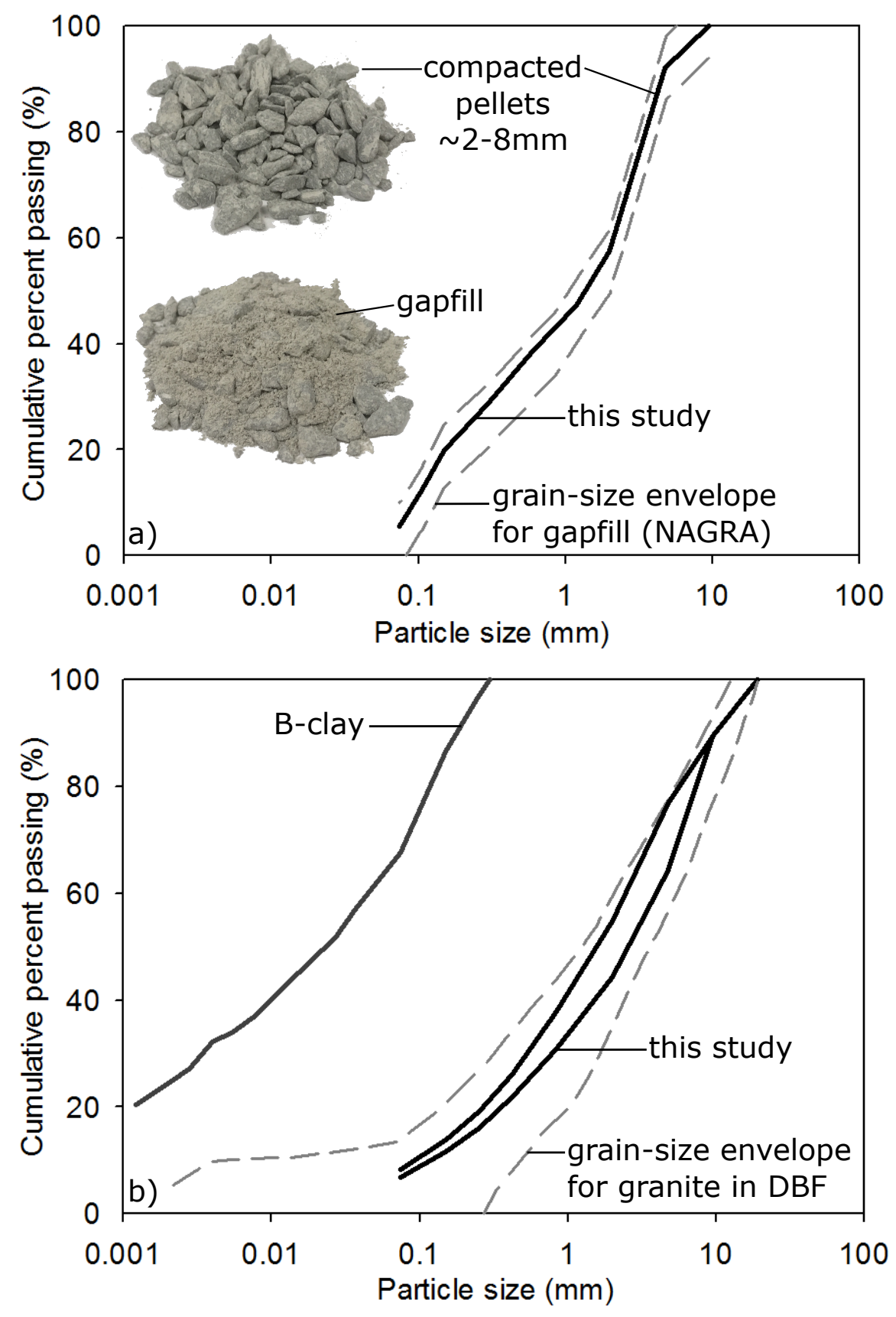

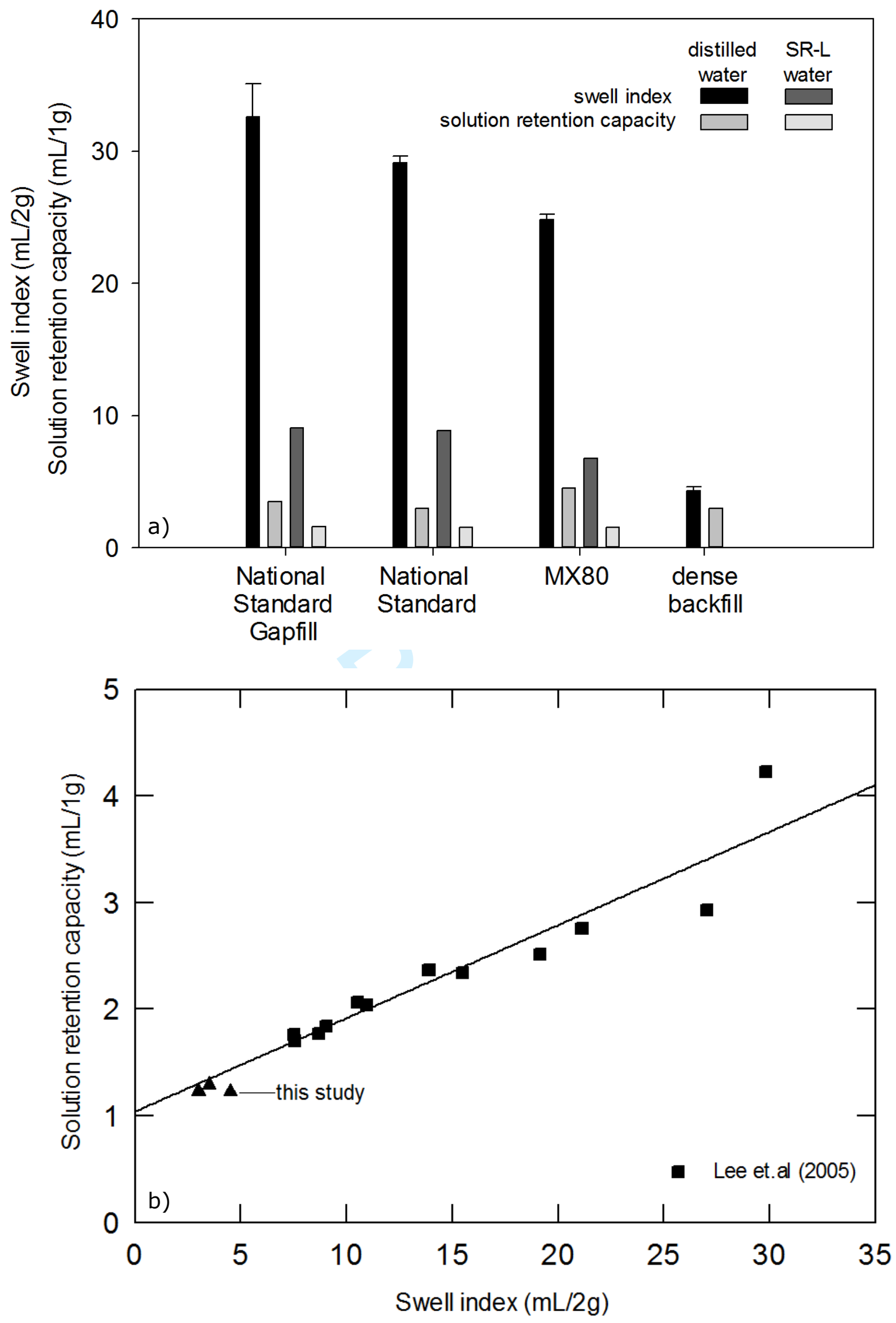


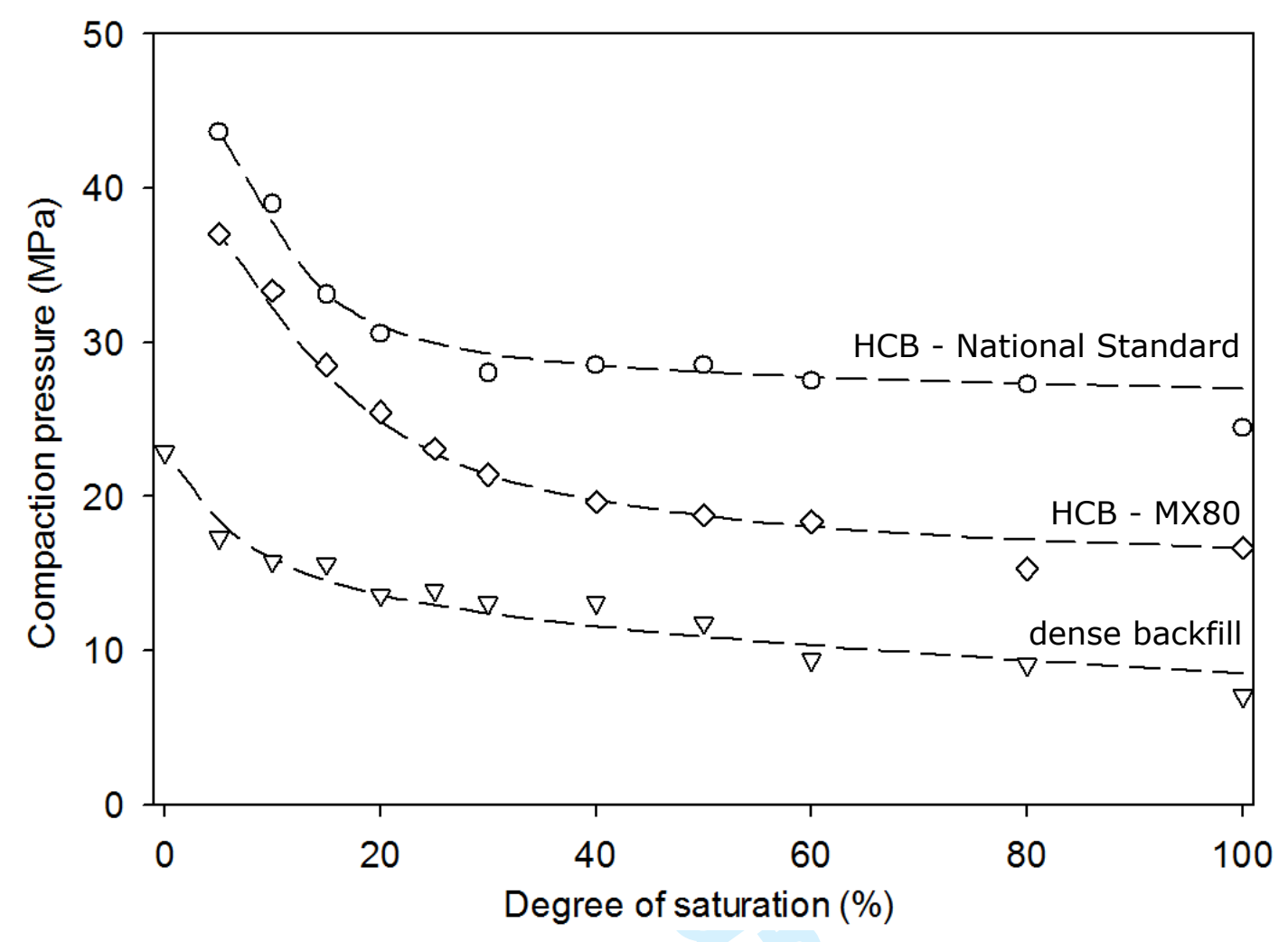




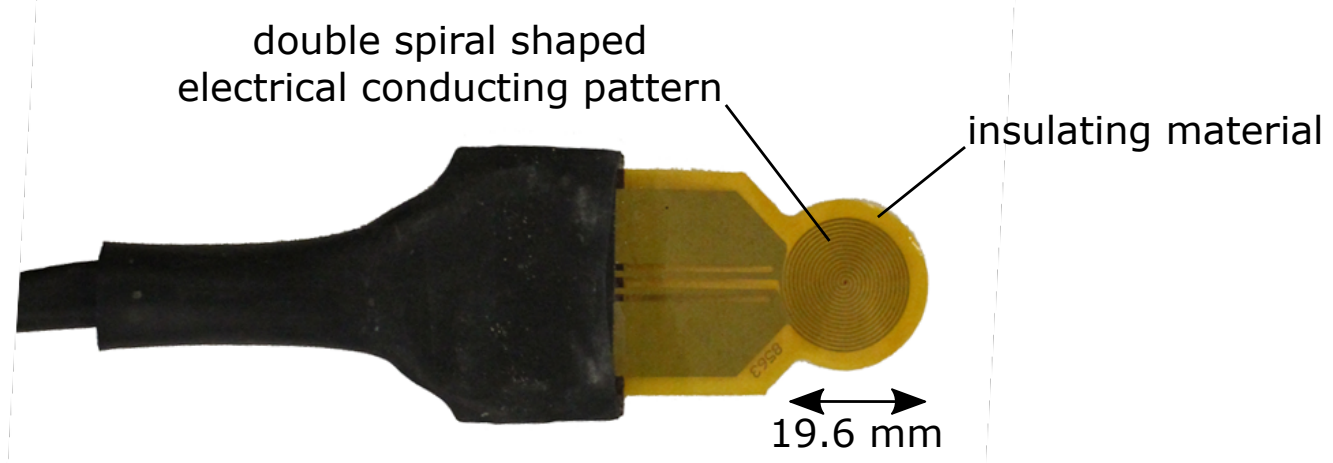

a) thermal property sensor for $25^{\circ} \mathrm{C}$ tests

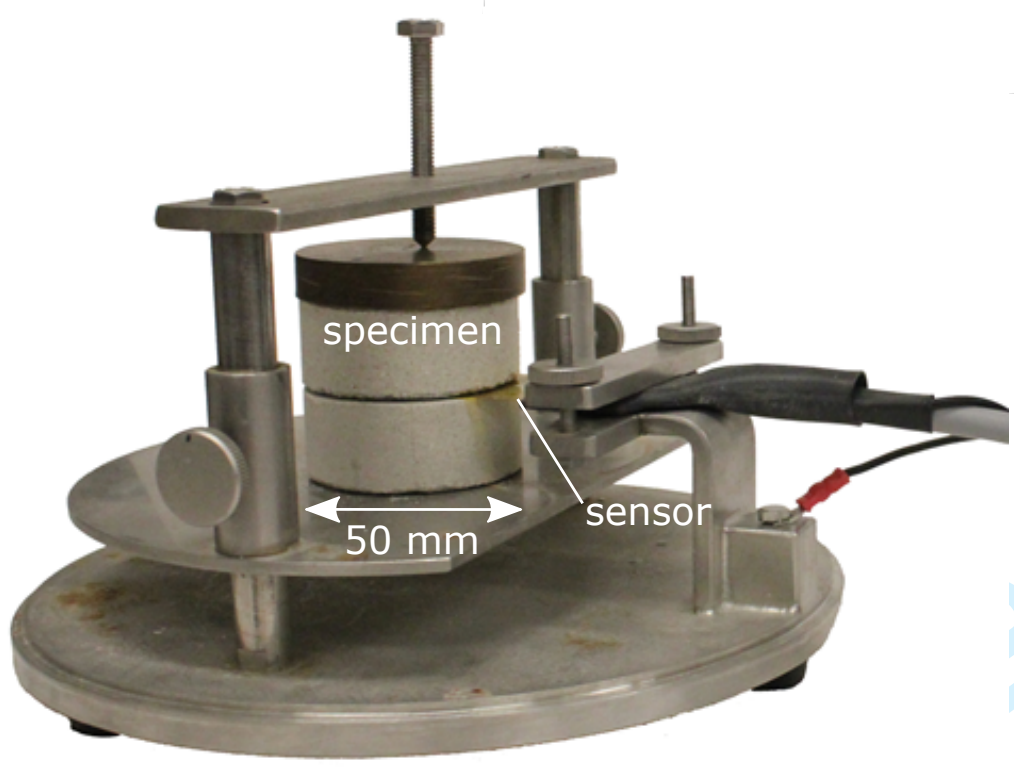

b) two-sided test

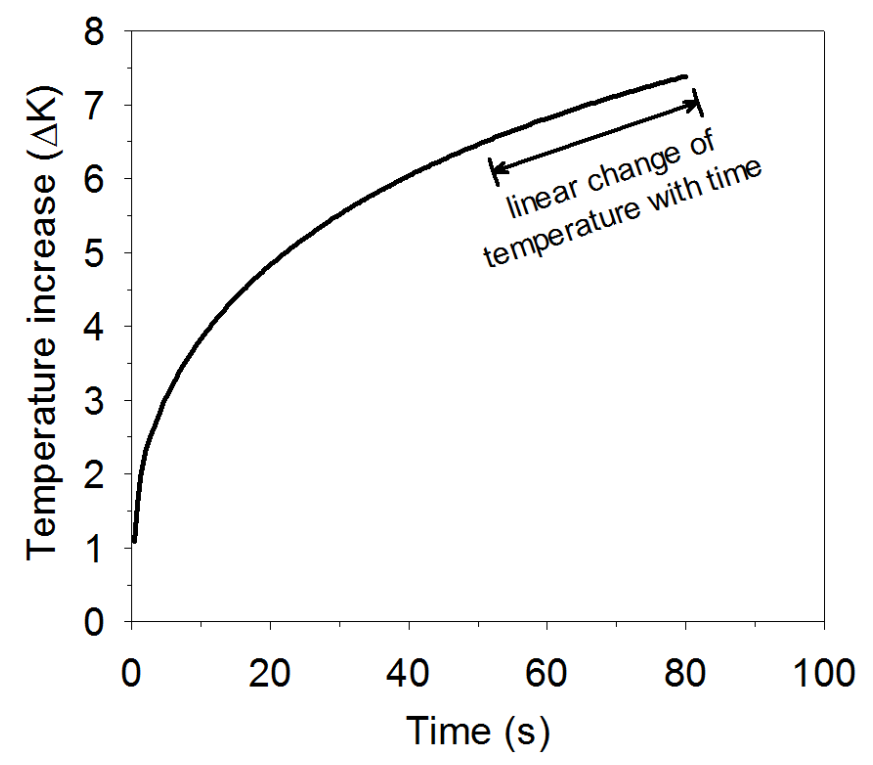

d)

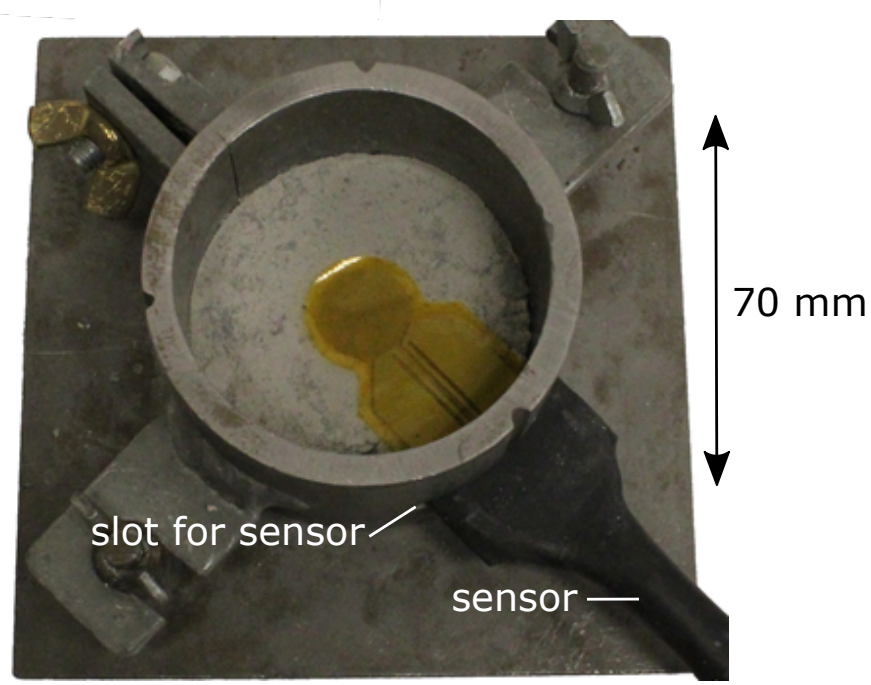

c) one-sided test

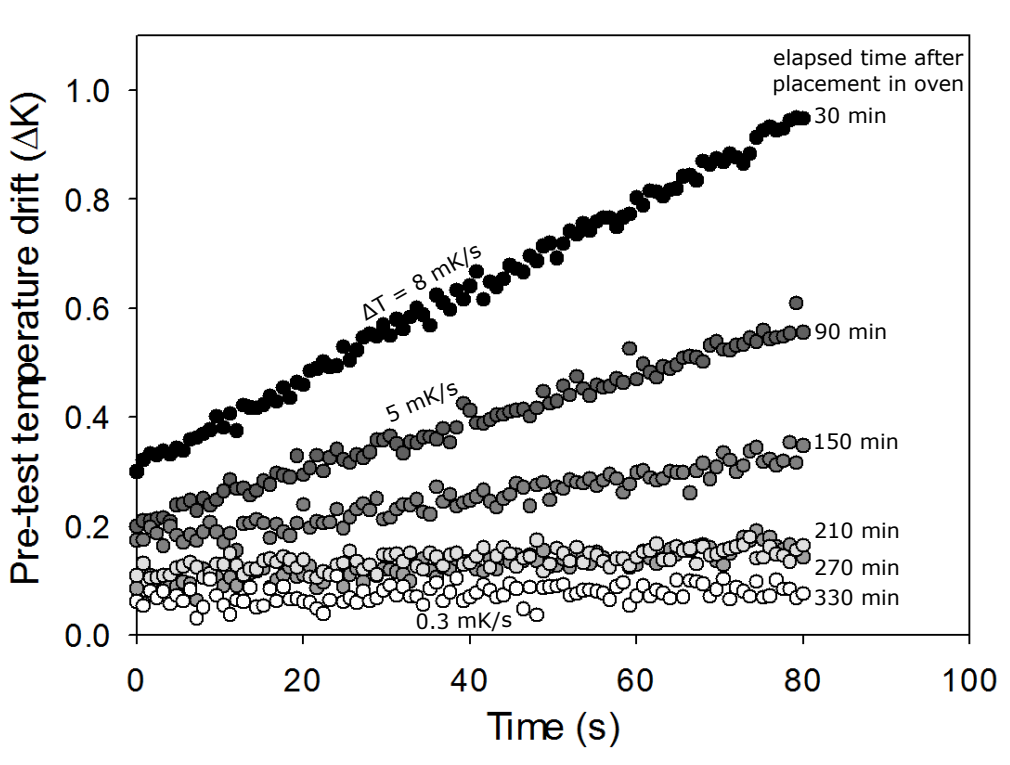

e) 


\section{Canadian Geotechnical Journal}
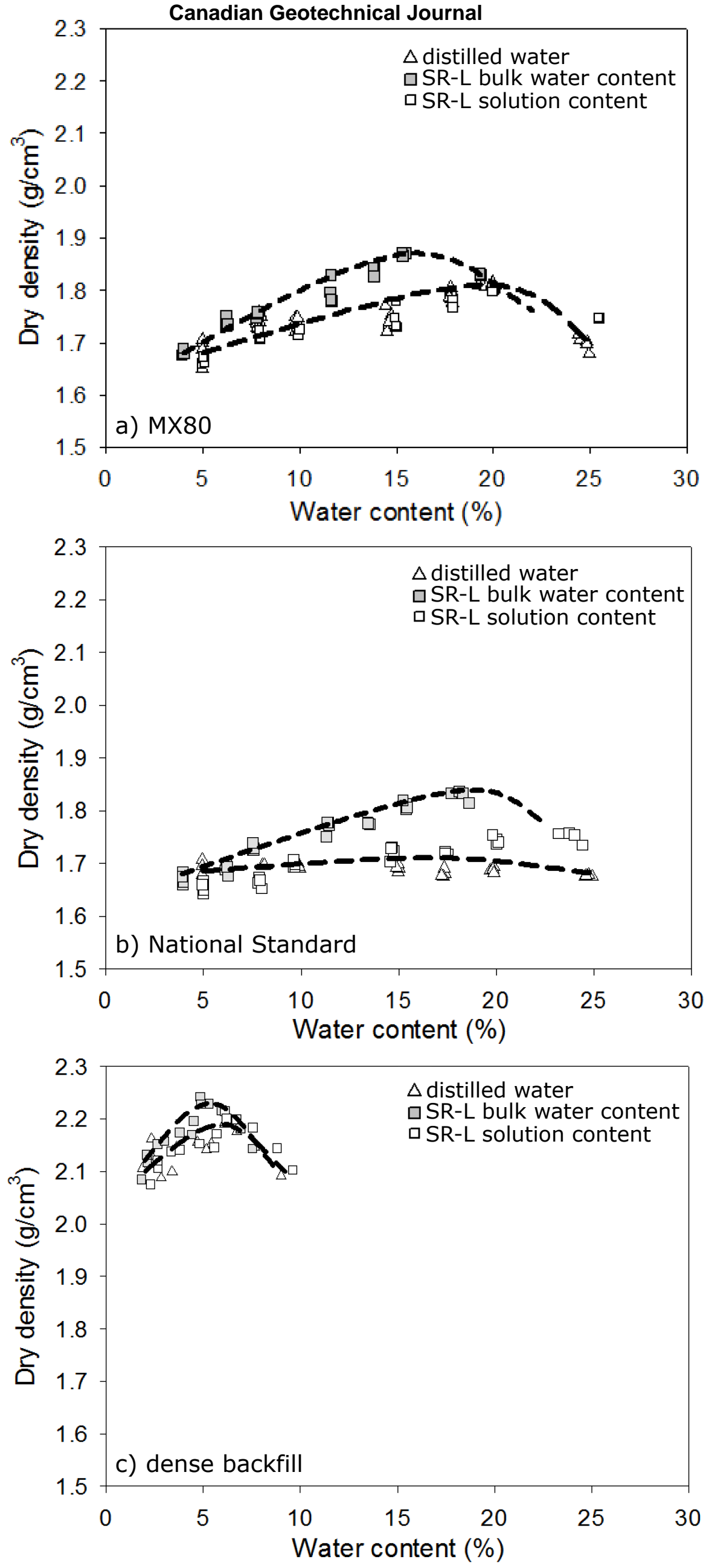

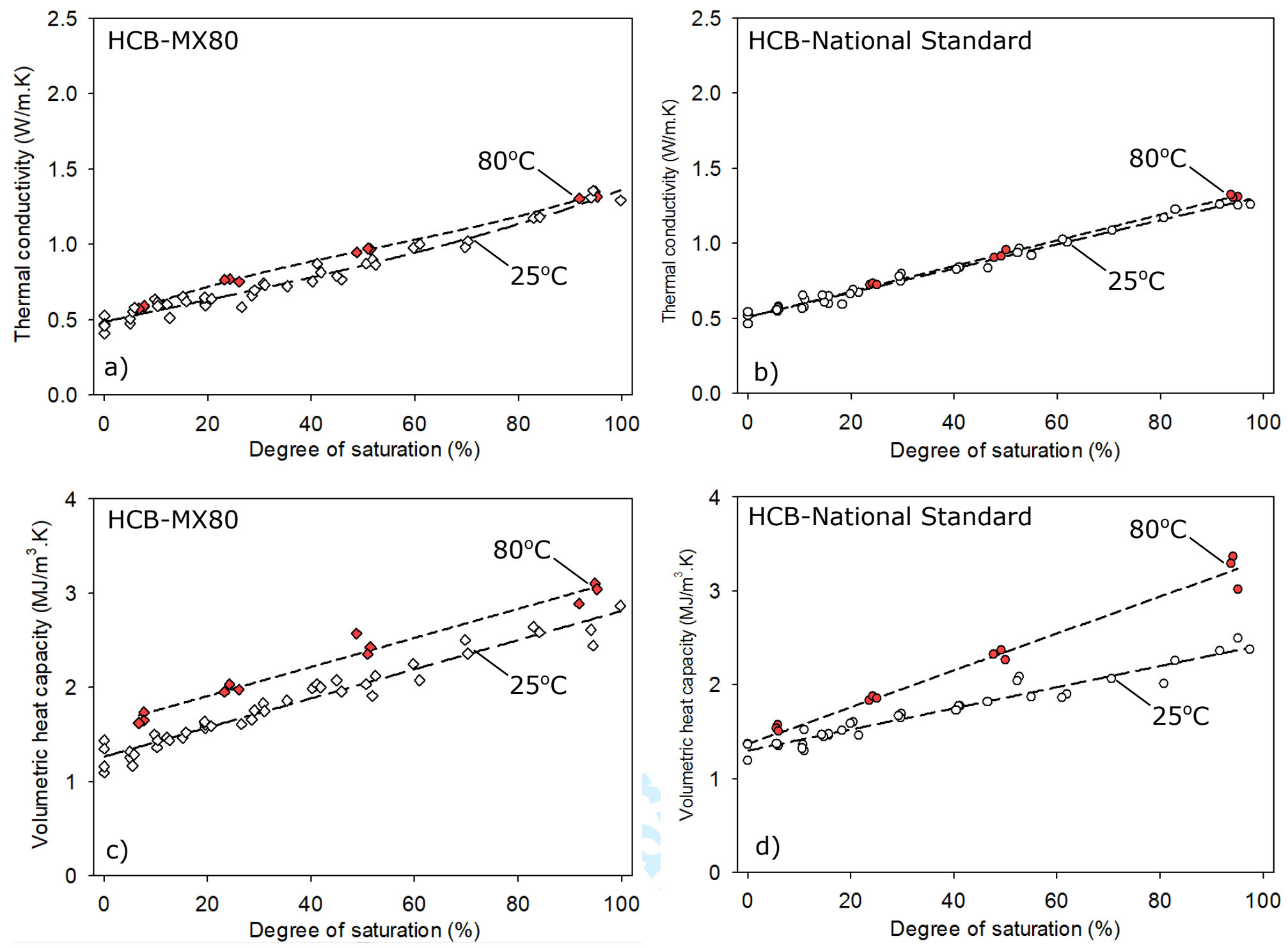

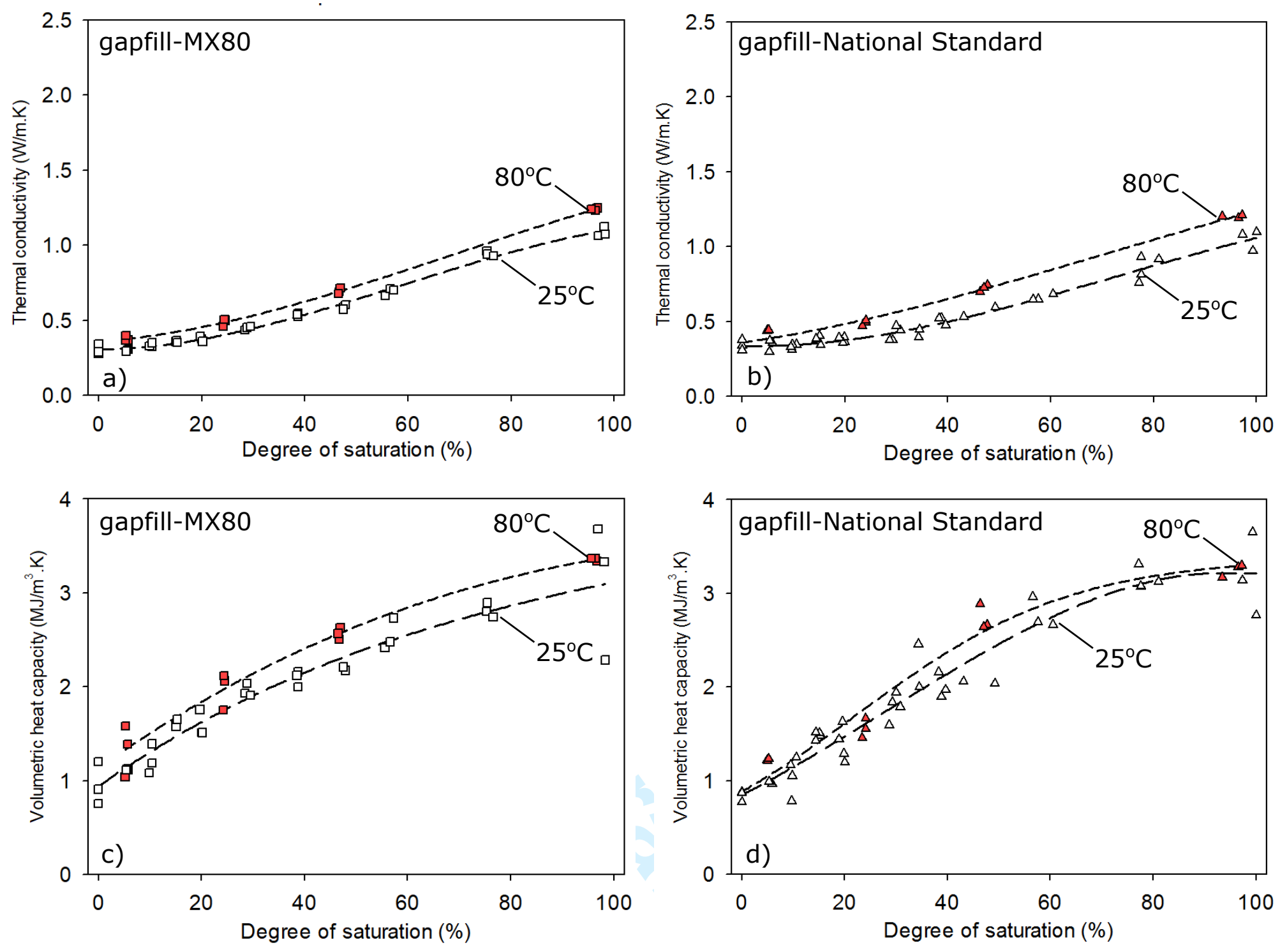

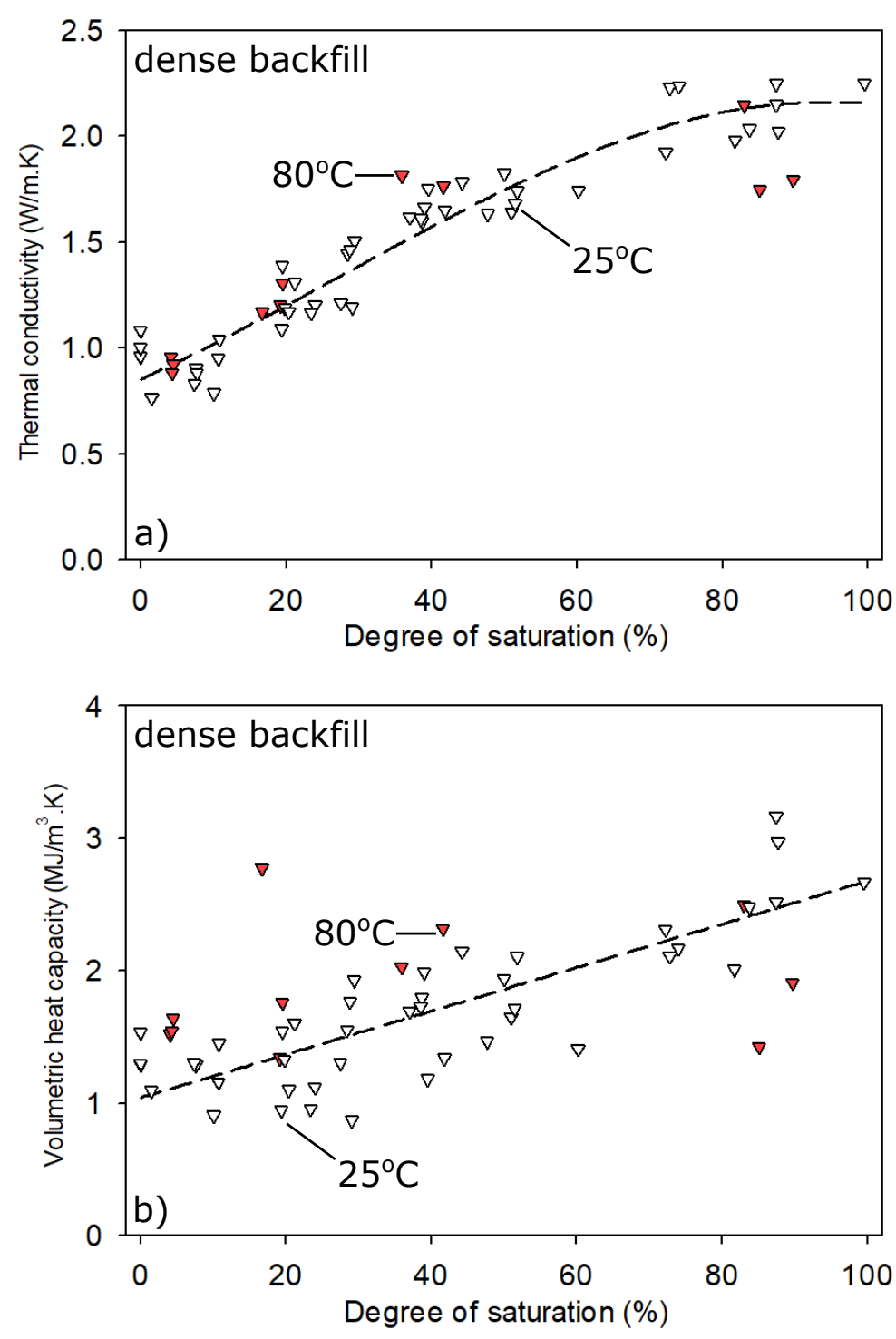

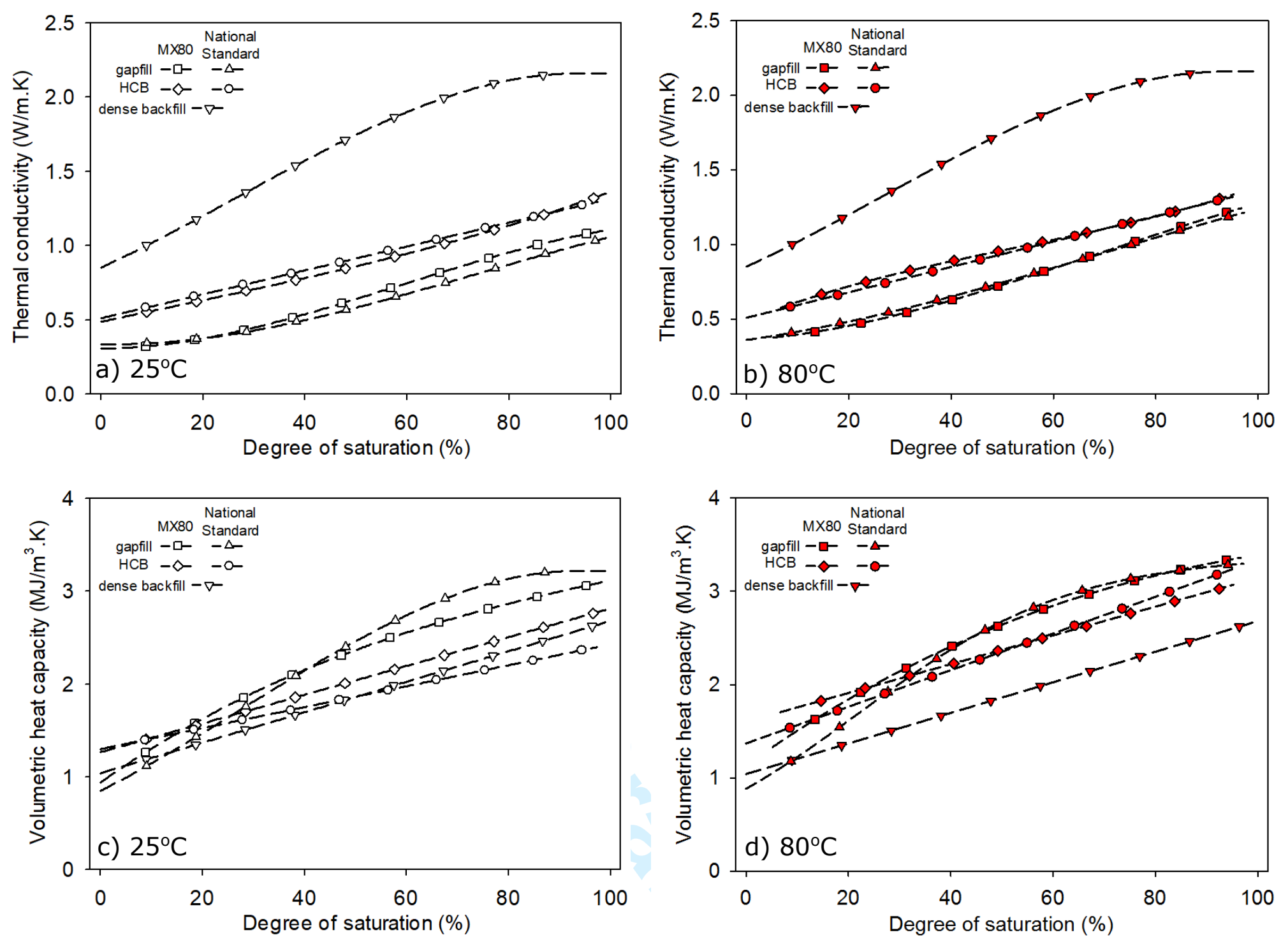


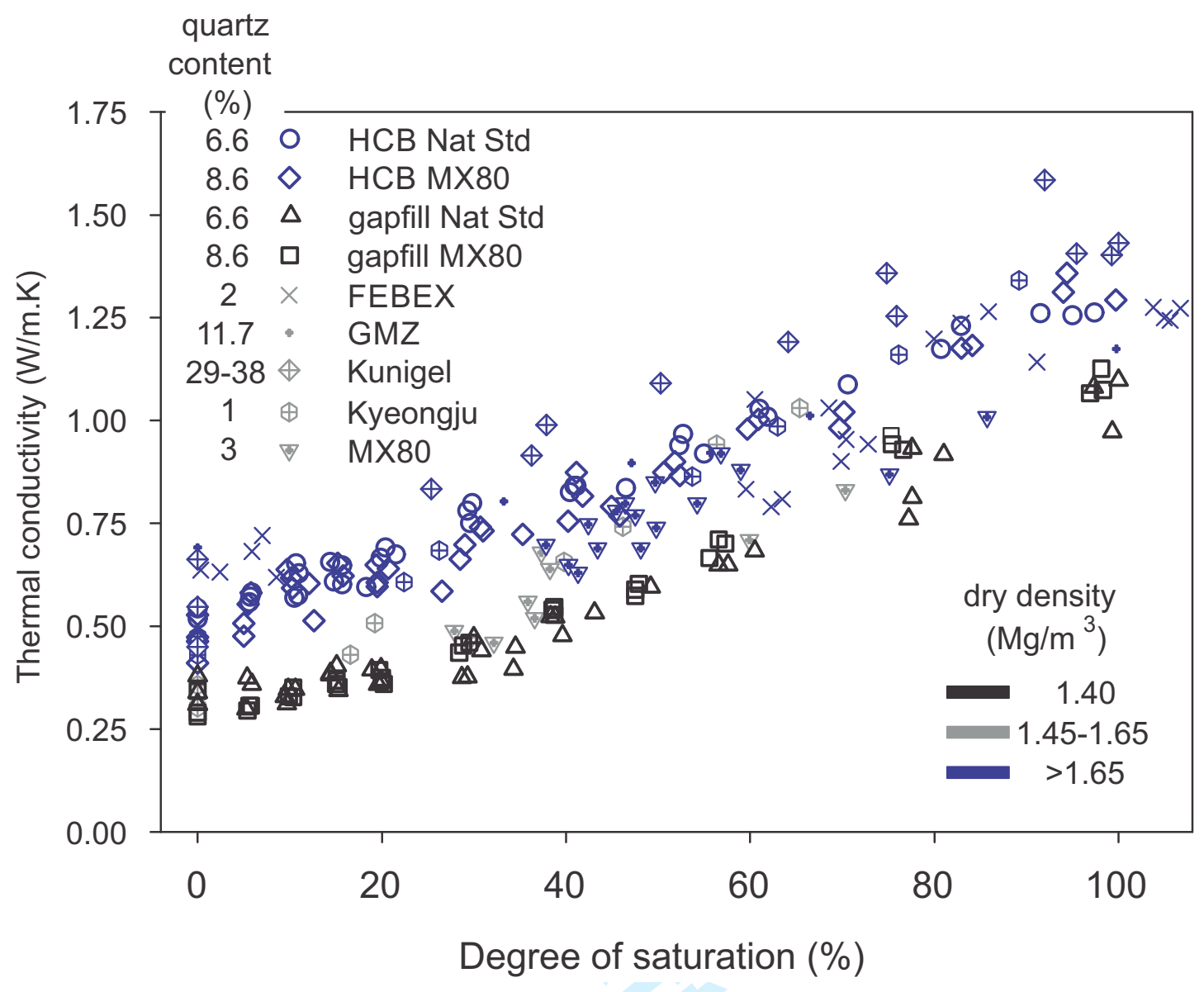



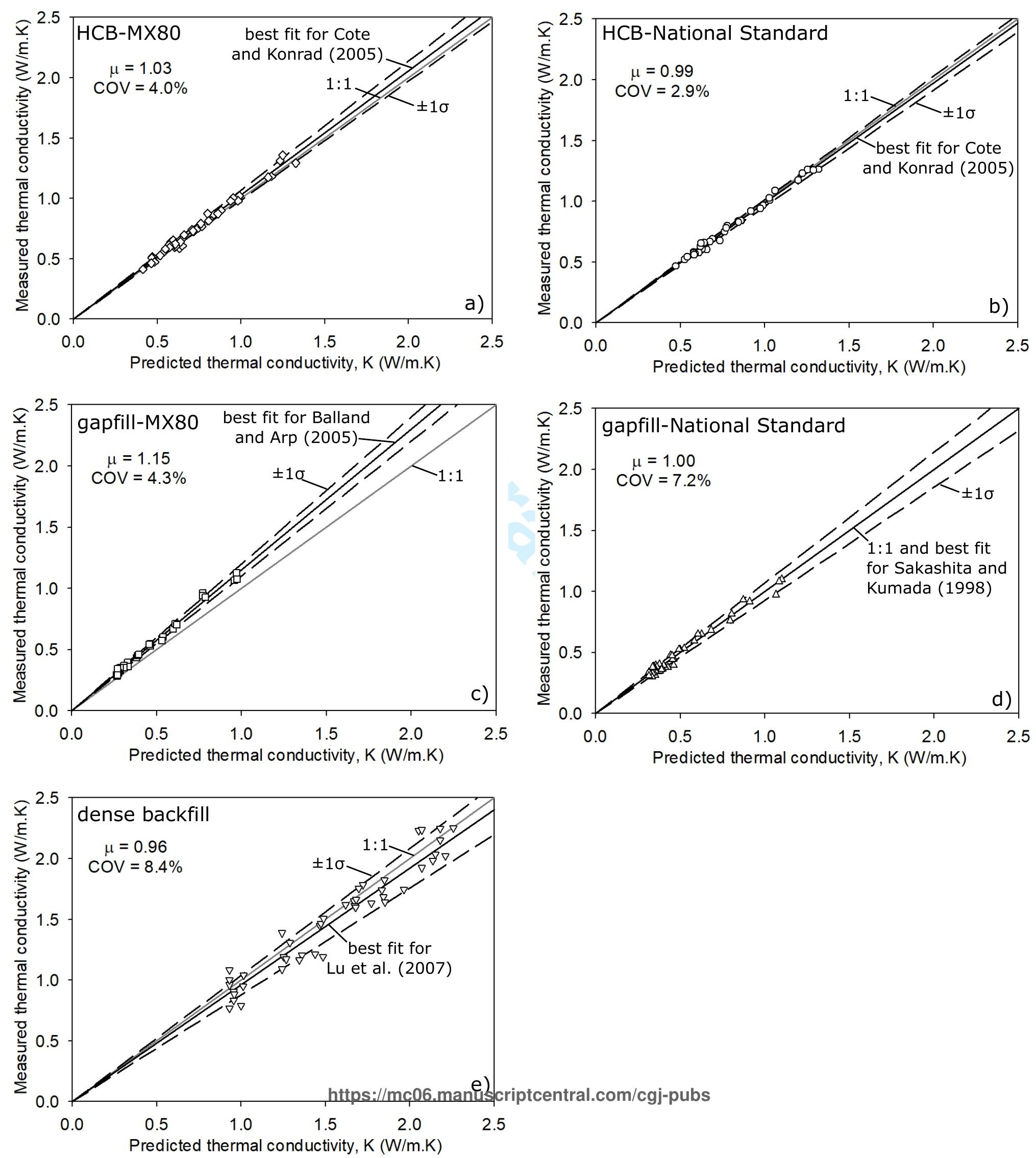